\title{
Two types of separation axioms on supra soft topological spaces
}

https://doi.org/10.1515/dema-2019-0016

Received October 7, 2018; accepted February 6, 2019

\begin{abstract}
In 2011, Shabir and Naz [1] employed the notion of soft sets to introduce the concept of soft topologies; and in 2014, El-Sheikh and Abd El-Latif [2] relaxed the conditions of soft topologies to construct a wider and more general class, namely supra soft topologies. In this disquisition, we continue studying supra soft topologies by presenting two kinds of supra soft separation axioms, namely supra soft $T_{i}$-spaces and supra p-soft $T_{i}$-spaces for $i=0,1,2,3,4$. These two types are formulated with respect to the ordinary points; and the difference between them is attributed to the applied non belong relations in their definitions. We investigate the relationships between them and their parametric supra topologies; and we provide many examples to separately elucidate the relationships among spaces of each type. Then we elaborate that supra p-soft $T_{i}$-spaces are finer than supra soft $T_{i}$-spaces in the case of $i=0,1,4$; and we demonstrate that supra soft $T_{3}$-spaces are finer than supra p-soft $T_{3}$-spaces. We point out that supra p-soft $T_{i}$-axioms imply supra p-soft $T_{i-1}$, however, this characterization does not hold for supra soft $T_{i}$-axioms (see, Remark (3.30)). Also, we give a complete description of the concepts of supra p-soft $T_{i}$-spaces $(i=1,2)$ and supra $p$-soft regular spaces. Moreover, we define the finite product of supra soft spaces and manifest that the finite product of supra soft $T_{i}$ (supra p-soft $T_{i}$ ) is supra soft $T_{i}$ (supra p-soft $T_{i}$ ) for $i=0,1,2$, 3 . After investigating some properties of these axioms in relation with some of the supra soft topological notions such as supra soft subspaces and enriched supra soft topologies, we explore the images of these axioms under soft $S^{\star}$-continuous mappings. Ultimately, we provide an illustrative diagram to show the interrelations between the initiated supra soft spaces.
\end{abstract}

Keywords: supra soft $T_{i}$-space, supra p-soft $T_{i}$-space, supra soft subspace, product supra soft spaces, supra soft topological space

MSC: 54D10, 54D15, 54D70

\section{Introduction}

The concept of soft sets [3] first appeared in 1999 as a virtual mathematical approach to overcome problems containing uncertainties or incomplete data. This approach is free from the difficulties that have troubled the existing mathematical approaches which utilized to solve problems associated with ambiguity such as fuzzy sets and rough sets. The theory of soft sets provides a general framework for modeling practical phenomena and brings about a rich potential for real life applications (see, for example, [4-6]).

Based on the soft set theory, the concept of soft topologies [1] was defined in 2011 as a new soft structure. Later on, many studies were carried out to study the properties of soft topologies and to compare them with those properties which exist via classical topologies (see, for example, [7-10]). In particular, the study of soft separation axioms was a great interest to researchers who studied this topic from many perspectives (see, for example, [11-14]). Recently, [15-18] corrected some errors related to soft separation axioms. The variety of the

^Corresponding Author: Tareq M. Al-shami: Department of Mathematics, Sana’a University, Sana’a, Yemen; E-mail: tareqalshami83@gmail.com

Mohammed E. El-Shafei: Department of Mathematics, Mansoura University, Mansoura, Egypt; E-mail: meshafei@hotmail.com 
study of the soft separation axioms is attributed to twofold: One is the distinguished objects that we desire to separate: Are they soft points or ordinary points?, and the second one is the nature of the belong and non belong relations which we utilized in the definitions: Are they natural belong or natural non belong or partial belong or total non belong relations?

The concept of supra topologies [19] was introduced in 1983 as a wider class of general topologies. Since then several studies were done on the supra topologies and their applications (see, for example, [20-25]). In connection to generalizing the crisp mathematical structures to the soft mathematical structures, the concept of supra soft topologies [2] was established in 2014 as an extension of supra topologies. Some fundamental notions via supra soft topologies such as supra soft continuity [2], supra soft compactness [26], various types of generalized supra soft open sets and supra soft separation axioms [27-31] were introduced and investigated. In 2017, Hosny and Al-Kadi [32] generated a supra soft topology from a soft topology by utilizing a soft stack. It turns out that the study of the properties of supra soft topologies has not yet taken its due attention and many fundamental supra soft topological notions need to be formulated and discussed.

It should be noted that the existing supra soft separation axioms were studied using the notion of soft points, so the current work aims to introduce two types of supra soft separation axioms with respect to ordinary points, namely supra soft $T_{i}$-spaces and supra p-soft $T_{i}$-spaces for $i=0,1,2,3$, 4. One of the motivations to study supra soft $T_{i}$-spaces is to establish a wider family which can be easily applied to classify the objects of study; and one of the motivations to study supra p-soft $T_{i}$-spaces is to point out the significant role of a total non belong relation in obtaining results similar to the ones achieved via supra topologies, and relaxing the conditions on the concept of supra soft regular spaces.

The layout of this article is as follows: In Section 1, we recall some definitions and properties of soft sets and supra soft topologies. In Section 2, we introduce the notions of supra soft $T_{i}$-spaces $(i=0,1,2,3,4)$; and study some properties. In Section 3, we introduce the notions of supra p-soft $T_{i}$-spaces $(i=0,1,2,3,4)$; and investigate some properties. Also, we elucidate their relationships to supra soft separation axioms which are presented in Section 2. Finally, we give a conclusion and make a plan for future works.

\section{Preliminaries}

In this section, we recall some definitions and results as they are important for the material of our study.

Definition 2.1. [3] A pair $(G, E)$ is said to be a soft set over a non-empty set $X$ provided that $G$ is a mapping of a set of parameters $E$ into $2^{X}$.

In this work, a soft set is denoted by $G_{E}$ instead of $(G, E)$ and it is identified as $G_{E}=\{(e, G(e)): e \in E$ and $\left.G(e) \in 2^{X}\right\}$. And the set of all soft sets over $X$ under a parameters set $E$, is denoted by $S\left(X_{E}\right)$.

Definition 2.2. [33] The relative complement of a soft set $G_{E}$, denoted by $G_{E}^{c}$, is given by $G_{E}^{c}=\left(G^{c}\right)_{E}$, where $G^{c}: E \rightarrow 2^{X}$ is a mapping defined by $G^{c}(e)=X \backslash G(e)$ for each $e \in E$.

Definition 2.3. [34] A soft set $G_{E}$ over $X$ is said to be a null soft set, denoted by $\widetilde{\Phi}$, if $G(e)=\emptyset$ for each $e \in E$. And its relative complement is said to be an absolute soft set, denoted by $\widetilde{X}$.

Definition 2.4. [33] The intersection of two soft sets $G_{A}$ and $F_{B}$ over $X$, denoted by $G_{A} \widetilde{\bigcap} F_{B}$, is a soft set $H_{D}$, where $D=A \bigcap B \neq \emptyset$, and a mapping $H: D \rightarrow 2^{X}$ is given by $H(d)=G(d) \bigcap F(d)$.

Definition 2.5. [34] The union of two soft sets $G_{A}$ and $F_{B}$ over $X$, denoted by $G_{A} \tilde{\bigcup} F_{B}$, is a soft set $H_{D}$, where $D=A \cup B$ and a mapping $H: D \rightarrow 2^{X}$ is given as follows:

$$
H(d)=\left\{\begin{array}{ccc}
G(d) & : & d \in A-B \\
F(d) & : & d \in B-A \\
G(d) \bigcup F(d) & : & d \in A \bigcap B
\end{array}\right.
$$


Definition 2.6. [35] A soft set $G_{A}$ is a soft subset of a soft set $F_{B}$, denoted by $G_{A} \widetilde{\subseteq} F_{B}$, if $A \subseteq B$ and for all $a \in A$, we have $G(a) \subseteq F(a)$.

The soft sets $G_{A}$ and $G_{B}$ are soft equal if each one of them is a soft subset of the other.

In the literature, there are many types of soft subsets, soft unions and soft intersections between two soft sets introduced and studied. For more details on this subject, we refer the reader to [36, 37] and the references mentioned therein.

Definition 2.7. $[9,10]$ A soft set $P_{E}$ over $X$ is called a soft point if there exists $e \in E$ and there exists $x \in X$ such that $P(e)=\{x\}$ and $P(\alpha)=\emptyset$ for each $\alpha \in E \backslash\{e\}$. A soft point will be shortly denoted by $P_{e}^{X}$.

Definition 2.8. [7] Let $G_{A}$ and $H_{B}$ be soft sets over $X$ and $Y$, respectively. Then the cartesian product of $G_{A}$ and $H_{B}$, denoted by $(G \times H)_{A \times B}$, is defined as $(G \times H)(a, b)=G(a) \times H(b)$ for each $(a, b) \in A \times B$.

Definition 2.9. [8] A soft mapping between $S\left(X_{A}\right)$ and $S\left(Y_{B}\right)$ is a pair $(f, \phi)$, denoted also by $f_{\phi}$, of mappings such that $f: X \rightarrow Y, \phi: A \rightarrow B$. Let $G_{A}$ and $H_{B}$ be soft subsets of $S\left(X_{A}\right)$ and $S\left(Y_{B}\right)$, respectively. Then the image of $G_{A}$ and pre-image of $H_{B}$ are defined by:

(i) $f_{\phi}\left(G_{A}\right)=\left(f_{\phi}(G)\right)_{B}$ is a soft subset of $S\left(Y_{B}\right)$ such that

$$
f_{\phi}(G)(b)=\left\{\begin{array}{cll}
\bigcup_{a \in \phi^{-1}(b)} f(G(a)) & : & \phi^{-1}(b) \neq \emptyset \\
\emptyset & : & \phi^{-1}(b)=\emptyset
\end{array}\right.
$$

for each $b \in B$.

(ii) $f_{\phi}^{-1}\left(H_{B}\right)=\left(f_{\phi}^{-1}(H)\right)_{A}$ is a soft subset of $S\left(X_{A}\right)$ such that $f_{\phi}^{-1}(H)(a)=f^{-1}(H(\phi(a)))$ for each $a \in A$.

Definition 2.10. [8] A soft mapping $f_{\phi}: S\left(X_{A}\right) \rightarrow S\left(Y_{B}\right)$ is said to be injective (resp. surjective, bijective) iff and $\phi$ are injective (resp. surjective, bijective).

Definition 2.11. [1] A soft set $x_{E}$ over $X$ is defined by $x(e)=\{x\}$ for each $e \in E$.

Definition 2.12. [1] The collection $\tau$ of soft sets over $X$ under a parameters set $E$ is said to be a soft topology on $X$ if the following three axioms hold:

(i) $\widetilde{X}$ and $\widetilde{\Phi}$ belong to $\tau$.

(ii) The union of an arbitrary family of soft sets in $\tau$ belongs to $\tau$.

(iii) The intersection of a finite family of soft sets in $\tau$ belongs to $\tau$.

The triple $(X, \tau, E)$ is called a soft topological space. Every member of $\tau$ is called a soft open set and its relative complement is called a soft closed set.

Definition 2.13. [1] For a soft set $G_{E}$ over $X$ and $x \in X$, we say that:

(i) $x \in G_{E}$ if $x \in G(e)$ for each $e \in E$.

(ii) $x \notin G_{E}$ if $x \notin G(e)$ for some $e \in E$.

Since there are other types of belong and non belong relations (see, Definition below), the notations $\epsilon$ and $\notin$ are called respectively natural belong and natural non belong relations.

Definition 2.14. [14] Let $G_{E}$ be a soft set over $X$ and $x \in X$. We say that:

(i) $x \Subset G_{E}$, reading as $x$ partially belongs to a soft set $G_{E}$, if $x \in G(e)$ for some $e \in E$.

(ii) $x \notin G_{E}$, reading as $x$ does not totally belong to a soft set $G_{E}$, if $x \notin G(e)$ for each $e \in E$. 
Definition 2.15. [14] A soft set $G_{E}$ over $X$ is said to be stable if there exists a subset $S$ of $X$ such that $G(e)=S$ for each $e \in E$.

Proposition 2.16. [14] Consider a soft mapping $f_{\phi}: S\left(X_{A}\right) \rightarrow S\left(Y_{B}\right)$ and let $G_{A}$ and $H_{B}$ be soft sets in $S\left(X_{A}\right)$ and $S\left(Y_{B}\right)$, respectively. Then the following statements hold.

(i) If $f$ is injective and $x \notin G_{A}$, then $f(x) \notin f_{\phi}\left(G_{A}\right)$.

(ii) If $\phi$ is surjective and $x \in G_{A}$, then $f(x) \in f_{\phi}\left(G_{A}\right)$.

(iii) If $f_{\phi}$ is injective and $x \notin G_{A}$, then $f(x) \notin f_{\phi}\left(G_{A}\right)$.

(iv) If $y \notin H_{B}$, then $x \notin f_{\phi}^{-1}\left(H_{B}\right)$ for each $x \in f^{-1}(y)$.

(v) If $y \in H_{B}$, then $x \in f_{\phi}^{-1}\left(H_{B}\right)$ for each $x \in f^{-1}(y)$.

(vi) If $\phi$ is surjective and $y \notin H_{B}$, then $x \notin f_{\phi}^{-1}\left(H_{B}\right)$ for each $x \in f^{-1}(y)$.

Definition 2.17. [2] The collection $\mu$ of soft sets over $X$ under a parameters set $E$ is said to be a supra soft topology on $X$ if it satisfies the first and second axioms of Definition (2.12).

The triple $(X, \mu, E)$ is called a supra soft topological space. Every member of $\mu$ is called a supra soft open set and its relative complement is called a supra soft closed set.

Definition 2.18. [2] For a soft subset $H_{E}$ of $(X, \mu, E)$, we define the following:

(i) $\operatorname{Int}_{\mu}\left(H_{E}\right)$ is the union of all supra soft open sets contained in $H_{E}$.

(ii) $\mathrm{Cl}_{\mu}\left(H_{E}\right)$ is the intersection of all supra soft closed sets containing $H_{E}$.

Theorem 2.19. [26] Let $H_{E}$ and $F_{E}$ be two soft subsets of $(X, \mu, E)$. Then:

(i) If $H_{E} \widetilde{\widetilde{\subseteq}} F_{E}$, then $C l_{\mu}\left(H_{E}\right) \widetilde{\subseteq} C l_{\mu}\left(F_{E}\right)$.

(ii) $P_{e}^{x} \in C l_{\mu}\left(H_{E}\right)$ if and only if $G_{E} \widetilde{\bigcap} H_{E} \neq \widetilde{\Phi}$ for each supra soft open set $G_{E}$ containing $P_{e}^{x}$.

Definition 2.20. [26] Let $(X, \mu, E)$ be a supra soft topological space and $Y$ be a non-empty subset of $X$. Then $\mu_{Y}=\left\{\widetilde{Y} \widetilde{\bigcap} G_{E}: G_{E} \in \mu\right\}$ is called a supra soft relative topology on $Y$ and $\left(Y, \mu_{Y}, E\right)$ is called a supra soft subspace of $(X, \mu, E)$.

Theorem 2.21. [26] Let $\left(Y, \mu_{Y}, E\right)$ be a supra soft subspace of $(X, \mu, E)$. Then $H_{E}$ is a supra soft closed subset of $\left(Y, \mu_{Y}, E\right)$ if and only if there exists a supra soft closed subset $F_{E}$ of $(X, \mu, E)$ such that $H_{E}=\widetilde{Y} \widetilde{\cap} F_{E}$.

Definition 2.22. [30] A supra soft topological space $(X, \mu, E)$ is called supra soft normal if for every two disjoint supra soft closed sets $H_{1_{E}}$ and $H_{2_{E}}$, there exist two disjoint supra soft open sets $G_{1_{E}}$ and $G_{2_{E}}$ such that $H_{1_{E}} \widetilde{\subseteq} G_{1_{E}}$ and $H_{2_{E}} \widetilde{\subseteq} G_{2_{E}}$.

\section{Supra soft $T_{i}$-spaces $(i=0,1,2,3,4)$}

In this section, we explain the notions of supra soft $T_{i}$-spaces $(i=0,1,2,3,4)$ and investigate their main properties. Also, we construct various examples to show the relationships between them and to clarify some obtained results.

Definition 3.1. A supra soft topological space $(X, \mu, E)$ is said to be:

(i) a supra soft $T_{0}$-space if for every $x \neq y \in X$, there exists a supra soft open set $G_{E}$ such that $x \in G_{E}, y \notin G_{E}$ or $y \in G_{E}, x \notin G_{E}$. 
(ii) a supra soft $T_{1}$-space if for every $x \neq y \in X$, there exist supra soft open sets $G_{E}$ and $F_{E}$ such that $x \in G_{E}, y \notin$ $G_{E}$ and $y \in F_{E}, x \notin F_{E}$.

(iii) a supra soft $T_{2}$-space if for every $x \neq y \in X$, there exist disjoint supra soft open sets $G_{E}$ and $F_{E}$ such that $x \in G_{E}, y \notin G_{E}$ and $y \in F_{E}, x \notin F_{E}$.

Proposition 3.2. Every supra soft $T_{i}$-space is a supra soft $T_{i-1}$-space, for $i=1,2$.

Proof. Straightforward.

The converse of the above proposition is not necessarily true as illustrated in the following example.

Example 3.3. Let $X=\{x, y\}$ be the universe set and $E=\left\{e_{1}, e_{2}\right\}$ be a fixed set of parameters. We define the three soft sets $F_{E}, G_{E}, H_{E}$ over $X$ as follows:

$$
\begin{aligned}
& F_{E}=\left\{\left(e_{1},\{x\}\right),\left(e_{2}, X\right)\right\} ; \\
& G_{E}=\left\{\left(e_{1},\{y\}\right),\left(e_{2}, \emptyset\right)\right\} \text { and } \\
& H_{E}=\left\{\left(e_{1}, X\right),\left(e_{2},\{y\}\right)\right\} .
\end{aligned}
$$

Then $\mu_{1}=\left\{\widetilde{\Phi}, \widetilde{X}, F_{E}, G_{E}\right\}$ and $\mu_{2}=\left\{\widetilde{\Phi}, \widetilde{X}, F_{E}, H_{E}\right\}$ are two supra soft topologies on $X$. Obviously, $\left(X, \mu_{1}, E\right)$ is a supra soft $T_{0}$-space and $\left(X, \mu_{2}, E\right)$ is a supra soft $T_{1}$-space. On the other hand, $x \neq y$ and there does not exist a supra soft open subset of $\left(X, \mu_{1}, E\right)$ containing $y$ such that $x$ does not belong to it. So $\left(X, \mu_{1}, E\right)$ is not supra soft $T_{1}$. Also, there do not exist two disjoint supra soft open subsets of $\left(X, \mu_{2}, E\right)$ such that one of them contains $x$ and the other contains $y$. So $\left(X, \mu_{2}, E\right)$ is not supra soft $T_{2}$.

Proposition 3.4. Let $(X, \mu, E)$ be a supra soft topological space. Then the collection $\mu_{e}=\left\{G(e): G_{E} \in \mu\right\}$ forms a supra topology on $X$ for each $e \in E$.

Proof. Straightforward.

Henceforth, we use the term a parametric supra topology for $\mu_{e}$ which given in the above proposition.

Proposition 3.5. If $(X, \mu, E)$ is a supra soft $T_{2}$-space, then a parametric supra topological space $\left(X, \mu_{e}\right)$ is supra $T_{2}$.

Proof. Let $x \neq y \in X$. Since $(X, \mu, E)$ is a supra soft $T_{2}$-space, then there exist disjoint supra soft open sets $F_{E}$ and $G_{E}$ containing $x$ and $y$, respectively. Therefore, $F(e)$ and $G(e)$ are disjoint supra soft open sets such that $x \in F(e)$ and $y \in G(e)$. This shows that $\left(X, \mu_{e}\right)$ is a supra $T_{2}$-space.

To see that the converse of the above proposition is not necessarily true, we give the following example.

Example 3.6. Assume that $X$ and $E$ are the same as in Example (3.3). Let the two soft sets $F_{E}, G_{E}$ over $X$ be given as follows:

$$
\begin{aligned}
& F_{E}=\left\{\left(e_{1},\{x\}\right),\left(e_{2},\{y\}\right)\right\} \text { and } \\
& G_{E}=\left\{\left(e_{1},\{y\}\right),\left(e_{2},\{x\}\right)\right\} .
\end{aligned}
$$

Then $\mu=\left\{\widetilde{\Phi}, \widetilde{X}, F_{E}, G_{E}\right\}$ is a supra soft topology on $X$. Since there does not exist a proper supra soft open subset of $\widetilde{X}$ containing $x$ or $y$, then $(X, \mu, E)$ is not a supra soft $T_{0}$-space. On the other hand, the two parametric supra topological spaces $\left(X, \mu_{e_{1}}\right)$ and $\left(X, \mu_{e_{2}}\right)$ are supra $T_{2}$.

We draw the attention of the reader to the fact that there is no a relationship between supra soft $T_{i}$-spaces and their parametric supra topological spaces in the case of $i=0,1$. This matter can be clarified in the following example. 
Example 3.7. One of the implications is illustrated in the above example.

In Example (3.3), it can be noted that $\left(X, \mu_{1_{e_{2}}}\right)$ is not supra $T_{0}$ in spite of $\left(X, \mu_{1}, E\right)$ being supra soft $T_{0}$. And $\left(X, \mu_{2_{e_{1}}}\right)$ and $\left(X, \mu_{2_{e_{2}}}\right)$ are not supra $T_{1}$ in spite of $\left(X, \mu_{2}, E\right)$ being supra soft $T_{1}$.

Definition 3.8. A supra soft topological space $(X, \mu, E)$ is said to be stable if every supra soft open set is stable.

Proposition 3.9. If $(X, \mu, E)$ is stable, then it is supra soft $T_{i}$ if and only if a parametric supra topological space $\left(X, \mu_{e}\right)$ is supra $T_{i}$ for each $i=0,1,2$.

Proof. We only prove the proposition in the case of $i=0$. The other cases follow similar lines.

Necessity: Suppose that $x \neq y$ in a supra soft $T_{0}$-space $(X, \mu, E)$. Then there exists a supra soft open subset $G_{E}$ of $(X, \mu, E)$ such that $x \in G_{E}, y \notin G_{E}$ or $y \in G_{E}, x \notin G_{E}$. Say, $x \in G_{E}, y \notin G_{E}$. Obviously, $G(e)$ is a supra open subset of $\left(X, \mu_{e}\right)$ and $x \in G(e)$ for each $e \in E$. Since $(X, \mu, E)$ is stable, then $y \notin G(e)$ for each $e \in E$. Thus, $\left(X, \mu_{e}\right)$ is supra $T_{0}$.

Sufficiency: Let $x \neq y$ in a supra $T_{0}$-space $\left(X, \mu_{e}\right)$. Then there exists a supra open subset $G$ of $\left(X, \mu_{e}\right)$ such that $x \in G, y \notin G$ or $y \in G, x \notin G$. Say, $x \in G, y \notin G$. By the stability of $(X, \mu, E)$, there is a supra soft open subset $M_{E}$ of $(X, \mu, E)$ such that $M(e)=G$ for each $e \in E$. Hence, $(X, \mu, E)$ is supra soft $T_{0}$.

The following result can be proved easily.

Proposition 3.10. If $(X, \mu, E)$ is a stable supra soft topological space, then $\mu_{e_{i}}=\mu_{e_{j}}$ for each $e_{i} \neq e_{j} \in E$.

Example (3.6) clarifies that the converse of the above proposition is not necessarily true.

Proposition 3.11. If $x_{E}$ is a supra soft closed subset of $(X, \mu, E)$ for each $x \in X$, then $(X, \mu, E)$ is a supra soft $T_{1}$-space.

Proof. Let $x \neq y \in X$ and let the given condition be satisfied. Then $x_{E}^{c}$ and $y_{E}^{c}$ are supra soft open sets such that $y \in x_{E}^{c}$ and $x \in y_{E}^{c}$. Clearly, $x \notin x_{E}^{c}$ and $y \notin y_{E}^{c}$. Hence, $(X, \mu, E)$ is a supra soft $T_{1}$-space.

In the next example, we point out that the converse of the above proposition need not be true in general.

Example 3.12. Assume that $\left(X, \mu_{2}, E\right)$ is the same as in Example (3.3). It can be seen that $x_{E}$ and $y_{E}$ are not supra soft closed sets in spite of $(X, \mu, E)$ being a supra soft $T_{1}$-space.

Proposition 3.13. If $(X, \mu, E)$ is a supra soft $T_{2}$-space, then $x_{E}$ is supra soft closed for each $x \in X$.

Proof. For each $y_{i} \in X \backslash\{x\}$, it follows that there exist disjoint supra soft open sets $G_{i E}$ and $F_{i E}$ such that $x \in G_{i E}$ and $y_{i} \in F_{i E}$. Therefore, $X \backslash\{x\}=\bigcup_{i \in I} F_{i}(e)$ for each $e \in E$. Thus, $\widetilde{\bigcup} F_{i E}=L_{E}$ is a supra soft open set, where $L(e)=X \backslash\{x\}$ for each $e \in E$. Hence, $x_{E}$ is supra soft closed.

The converse of the above proposition fails as demonstrated in the next example.

Example 3.14. Assume that $X=\{x, y, z\}$ and $E=\left\{e_{1}, e_{2}\right\}$; and let the three soft sets $F_{E}, G_{E}, H_{E}$ over $X$ be given as follows:

$$
\begin{aligned}
& F_{E}=\left\{\left(e_{1},\{x, y\}\right),\left(e_{2},\{x, y\}\right)\right\} ; \\
& G_{E}=\left\{\left(e_{1},\{x, z\}\right),\left(e_{2},\{x, z\}\right)\right\} \text { and } \\
& H_{E}=\left\{\left(e_{1},\{y, z\}\right),\left(e_{2},\{y, z\}\right)\right\} .
\end{aligned}
$$

Then $\mu=\left\{\widetilde{\Phi}, \widetilde{X}, F_{E}, G_{E}, H_{E}\right\}$ is a supra soft topology on X. Obviously, $x_{E}, y_{E}$ and $z_{E}$ are supra soft closed sets. On the other hand, $(X, \mu, E)$ is not a supra soft $T_{2}$-space.

Theorem 3.15. $(X, \mu, E)$ is a supra soft $T_{2}$-space if and only if for each $x \neq y$, there exists a supra soft open set $G_{E}$ such that $x \in G_{E}$ and $y \notin C l_{\mu}\left(G_{E}\right)$. 
Proof. Necessity: For each $x \neq y$ in a supra soft $T_{2}$-space, there exist supra soft open sets $G_{E}$ and $F_{E}$ such that $x \in G_{E}, y \in F_{E}$ and $G_{E} \widetilde{\bigcap} F_{E}=\widetilde{\emptyset}$. Now, $G_{E} \widetilde{\subseteq} F_{E}^{c}$ implies that $C l_{\mu}\left(G_{E}\right) \widetilde{\subseteq} F_{E}^{c}$. Since $y \notin F^{c}(e)$ for each $e \in E$, then $y \notin C l_{\mu}\left(G_{E}\right)$.

Sufficiency: Let $x \neq y \in X$ and $G_{E}$ be a supra soft open set such that $x \in G_{E}$ and $y \notin C l_{\mu}\left(G_{E}\right)$. Put $C l_{\mu}\left(G_{E}\right)=H_{E}$. Now, $y \in H_{E}^{c}$ and $H_{E}^{c}$ is supra soft open. Then $C l_{\mu}\left(G_{E}\right) \widetilde{\bigcap} H_{E}^{c}=\widetilde{\Phi}$. This shows that $(X, \mu, E)$ is a supra soft $T_{2^{-}}$ space.

Hereafter, we define supra soft regular spaces and characterize them.

Definition 3.16. A supra soft topological space $(X, \mu, E)$ is said to be supra soft regular if for every supra soft closed set $H_{E}$ and $x \in X$ such that $x \notin H_{E}$, there exist disjoint supra soft open sets $G_{E}$ and $F_{E}$ such that $H_{E} \widetilde{\subseteq} G_{E}$ and $x \in F_{E}$.

Proposition 3.17. For each supra soft open or supra soft closed subset $G_{E}$ of a supra soft regular space $(X, \mu, E)$, we have $x \in G_{E}$ if and only if $x \Subset G_{E}$.

Proof. Necessity: In view of the Definition (2.13) and Definition (2.14), we find that $x \in G_{E}$ implies $x \Subset G_{E}$ for any soft set $G_{E}$.

Sufficiency: Consider $G_{E}$ is a supra soft open set and let $x \Subset G_{E}$. Then we have two cases:

Case $1 x \in G(e)$ for each $e \in E$. Thus, the result holds.

Case 2 There exists $e \in E$ such that $x \notin G(e)$. Now, $x \notin G_{E}^{c}$. Since $(X, \mu, E)$ is supra soft regular, then there exist disjoint supra soft open sets $V_{E}$ and $W_{E}$ such that $G_{E}^{c} \widetilde{\subseteq} V_{E}$ and $x \in W_{E}$. Since $x \notin G(e)$, we obtain $V(e) \cap W(e) \neq \emptyset$. But this contradicts the disjointness of $V_{E}$ and $W_{E}$. Thus, it must be that $x \in G(e)$ for each $e \in E$.

The sufficient condition in the case of $G_{E}$ being a supra soft closed set can be proven in a similar way.

Corollary 3.18. Every supra soft regular space $(X, \mu, E)$ is stable.

Corollary 3.19. If $(X, \mu, E)$ is a supra soft regular space, then the parametric supra topologies $\mu_{e}$ are equal for each $e \in E$.

Corollary 3.20. A finite supra soft regular space $(X, \mu, E)$ contains at most $2^{|X|}$ supra soft open sets.

Example (3.14) clarifies that the converse of Corollary (3.18) and Corollary (3.19) is not always true; and Example (3.6) clarifies that the converse of Corollary (3.20) is not always true.

Proposition 3.21. If $(X, \mu, E)$ is a supra soft regular space, then for each $P_{e}^{X} \in X$ and supra soft open set $F_{E}$ containing $P_{e}^{X}$, there exists a supra soft open set $G_{E}$ such that $x \in G_{E} \widetilde{\widetilde{C}} C l_{\mu}\left(G_{E}\right) \widetilde{\widetilde{\subseteq}} F_{E}$.

Proof. Let $x \in X$ and $F_{E}$ be a supra soft open set containing $P_{e}^{x}$. Then $F_{E}^{c}$ is supra soft closed and $x \notin F_{E}^{c}$. Therefore, there are disjoint supra soft open sets $W_{E}$ and $G_{E}$ such that $F_{E}^{c} \widetilde{\subseteq} W_{E}$ and $x \in G_{E}$. Therefore, $G_{E} \widetilde{\subseteq} W_{E}^{c} \widetilde{\subseteq} F_{E}$. Thus, $C l_{\mu}\left(G_{E}\right) \widetilde{\widetilde{\subseteq}} W_{E}^{c} \widetilde{\simeq} F_{E}$.

The converse of the above proposition need not be true in general as shown in the next example.

Example 3.22. Assume that $(X, \mu, E)$ is the same as in Example (3.6). Then it can be seen that for each supra soft open set $F_{E}$ containing $x$, there exists a supra soft open set $G_{E}$ such that $x \in G_{E} \widetilde{\subseteq} C l_{\mu}\left(G_{E}\right) \widetilde{\subseteq} F_{E}$. On the other hand, $(X, \mu, E)$ is not a supra soft regular space.

Theorem 3.23. For any supra soft regular space $(X, \mu, E)$, the following three statements are equivalent:

(i) $(X, \mu, E)$ is a supra soft $T_{2}$-space.

(ii) $(X, \mu, E)$ is a supra soft $T_{1}$-space. 
(iii) $(X, \mu, E)$ is a supra soft $T_{0}$-space.

Proof. Obviously, (i) $\rightarrow$ (ii) $\rightarrow$ (iii).

(iii) $\rightarrow$ (i): Let $x \neq y \in X$ and $(X, \mu, E)$ be a supra soft $T_{0}$-space. Then there exists a supra soft open set $G_{E}$ such that $x \in G_{E}$ and $y \notin G_{E}$, or $y \in G_{E}$ and $x \notin G_{E}$. Say, $x \in G_{E}$ and $y \notin G_{E}$. By Proposition (3.17), we find that $y \notin G_{E}$. Now, we have $x \notin G_{E}^{c}$ and $y \in G_{E}^{c}$. Since $(X, \mu, E)$ is supra soft regular, then there exist two disjoint supra soft open sets $W_{1_{E}}$ and $W_{2_{E}}$ such that $x \in W_{1_{E}}$ and $y \in G_{E}^{c} \widetilde{\subseteq} W_{2_{E}}$. This completes the proof.

Definition 3.24. A supra soft topological space $(X, \mu, E)$ is said to be:

(i) a supra soft $T_{3}$ if it is both supra soft regular and supra soft $T_{1}$.

(ii) a supra soft $T_{4}$ if it is both supra soft normal and supra soft $T_{1}$.

Proposition 3.25. Every supra soft $T_{3}$-space is supra soft $T_{2}$.

Proof. It follows directly from Theorem (3.23).

Corollary 3.26. If $(X, \mu, E)$ is a supra soft $T_{3}$-space, then $x_{E}$ is supra soft closed for all $x \in X$.

The converse of the above proposition need not true in general as shown in the next example.

Example 3.27. Assume that $X=\{x, y, z\}$ and $E=\left\{e_{1}, e_{2}\right\}$; and let the soft sets $\left\{F_{i E}: i=1,2, \ldots, 6\right\}$ over $X$ be given as follows:

$$
\begin{aligned}
& F_{1 E}=\left\{\left(e_{1},\{x\}\right),\left(e_{2},\{x\}\right)\right\} ; \\
& F_{2 E}=\left\{\left(e_{1},\{y\}\right),\left(e_{2},\{y\}\right)\right\} ; \\
& F_{3 E}=\left\{\left(e_{1},\{x, y\}\right),\left(e_{2},\{x, y\}\right)\right\} ; \\
& F_{4 E}=\left\{\left(e_{1},\{x, z\}\right),\left(e_{2},\{x, z\}\right)\right\} ; \\
& F_{5 E}=\left\{\left(e_{1},\{y, z\}\right),\left(e_{2},\{y, z\}\right)\right\} \text { and } \\
& F_{6 E}=\left\{\left(e_{1},\{x, y\}\right),\left(e_{2}, X\right)\right\} .
\end{aligned}
$$

Then $\mu=\left\{\widetilde{\Phi}, \widetilde{X}, F_{i E}: i=1,2, \ldots, 6\right\}$ is a supra soft topology on $X$. Obviously, $(X, \mu, E)$ is a supra soft $T_{2}$-space. On the other hand, $F_{6 E}^{c}$ is a supra soft closed set such that $z \notin F_{6 E}^{c}$. Since there are no two disjoint supra soft open sets such that one of them contains $z$ and the other contains $F_{6 E}^{c}$, then $(X, \mu, E)$ is not a supra soft regular space. Hence, it is not a supra soft $T_{3}$-space.

Theorem 3.28. If $(X, \mu, E)$ is a supra soft $T_{3}$-space, then a parametric supra topological space $\left(X, \mu_{e}\right)$ is supra $T_{3}$ for each $e \in E$.

Proof. Since $(X, \mu, E)$ is supra soft $T_{3}$, then it is stable. So, from Proposition (3.9), we find that $\left(X, \mu_{e}\right)$ is supra $T_{1}$. It remains to prove the supra regularity of $\left(X, \mu_{e}\right)$. Suppose that $H$ is a supra closed subset of $X$ such that $x \notin H$. By Corollary (3.18), there exists a supra soft closed set $F_{E}$ such that $F(e)=H$ for each $e \in E$. Obviously, $x \notin F_{E}$. By hypothesis, there exist two disjoint supra soft open sets $G_{E}$ and $W_{E}$ such that $x \in G_{E}$ and $F_{E} \widetilde{\widetilde{\subseteq}} W_{E}$. This means that $G(e)$ and $W(e)$ are two disjoint supra open subsets of $\left(X, \mu_{e}\right)$ such that $x \in G(e)$ and $F(e)=H \subseteq W(e)$. Thus, $\left(X, \mu_{e}\right)$ is supra regular. Hence, $\left(X, \mu_{e}\right)$ is supra $T_{3}$.

The converse of the above theorem is not necessarily true as illustrated in the following example.

Example 3.29. Assume that $(X, \mu, E)$ is the same as in Example (3.27). Then the two parametric supra topologies $\mu_{e_{1}}=\mu_{e_{2}}=\{\emptyset, X,\{x\},\{y\},\{x, y\},\{x, z\},\{y, z\}\}$ are supra $T_{3}$-spaces. On the other hand, we demonstrate in Example (3.27) that $(X, \mu, E)$ is not a supra soft $T_{3}$-space.

Remark 3.30. We prove that the concepts of supra soft $T_{3}$-spaces and supra soft $T_{4}$-spaces are independent of each other, using the two examples below. 
Example 3.31. Assume that $(X, \mu, E)$ is the same as in Example (3.27). We clarify that $(X, \mu, E)$ is supra soft $T_{2}$, but it is not supra soft $T_{3}$. On the other hand, the collection of all supra soft closed subsets of $(X, \mu, E)$ is $\left\{\widetilde{\Phi}, \widetilde{X}, F_{1 E}, F_{2 E}, F_{3 E}^{c}, F_{4 E}, F_{5 E}, F_{6 E}^{c}\right\}$. It can be shown that $(X, \mu, E)$ is supra soft normal. Moreover, it is supra soft $T_{4}$.

Example 3.32. Assume that $X=\{v, w, x, y, z\}$ and $E=\left\{e_{1}, e_{2}\right\}$; and let the soft sets $\left\{F_{i E}: i=1,2, \ldots, 23\right\}$ over $X$ be given as follows:

$$
\begin{aligned}
& F_{1 E}=\left\{\left(e_{1},\{v, x\}\right),\left(e_{2},\{v, x\}\right)\right\} ; \\
& F_{2 E}=\left\{\left(e_{1},\{v, y\}\right),\left(e_{2},\{v, y\}\right)\right\} ; \\
& F_{3 E}=\left\{\left(e_{1},\{v, z\}\right),\left(e_{2},\{v, z\}\right)\right\} ; \\
& F_{4 E}=\left\{\left(e_{1},\{w, x\}\right),\left(e_{2},\{w, x\}\right)\right\} ; \\
& F_{5 E}=\left\{\left(e_{1},\{w, y\}\right),\left(e_{2},\{w, y\}\right)\right\} ; \\
& F_{6 E}=\left\{\left(e_{1},\{w, z\}\right),\left(e_{2},\{w, z\}\right)\right\} ; \\
& F_{7 E}=\left\{\left(e_{1},\{x, y\}\right),\left(e_{2},\{x, y\}\right)\right\} ; \\
& F_{8 E}=\left\{\left(e_{1},\{x, z\}\right),\left(e_{2},\{x, z\}\right)\right\} ; \\
& F_{9 E}=\left\{\left(e_{1},\{v, w, x\}\right),\left(e_{2},\{v, w, x\}\right)\right\} ; \\
& F_{10 E}=\left\{\left(e_{1},\{v, w, y\}\right),\left(e_{2},\{v, w, y\}\right)\right\} ; \\
& F_{11 E}=\left\{\left(e_{1},\{v, w, z\}\right),\left(e_{2},\{v, w, z\}\right)\right\} ; \\
& F_{12 E}=\left\{\left(e_{1},\{v, x, y\}\right),\left(e_{2},\{v, x, y\}\right)\right\} ; \\
& F_{13 E}=\left\{\left(e_{1},\{v, x, z\}\right),\left(e_{2},\{v, x, z\}\right)\right\} ; \\
& F_{14 E}=\left\{\left(e_{1},\{v, y, z\}\right),\left(e_{2},\{v, y, z\}\right)\right\} ; \\
& F_{15 E}=\left\{\left(e_{1},\{w, x, y\}\right),\left(e_{2},\{w, x, y\}\right)\right\} ; \\
& F_{16 E}=\left\{\left(e_{1},\{w, x, z\}\right),\left(e_{2},\{w, x, z\}\right)\right\} ; \\
& F_{17 E}=\left\{\left(e_{1},\{w, y, z\}\right),\left(e_{2},\{w, y, z\}\right)\right\} ; \\
& F_{18 E}=\left\{\left(e_{1},\{x, y, z\}\right),\left(e_{2},\{x, y, z\}\right)\right\} ; \\
& F_{19 E}=\left\{\left(e_{1},\{v, w, x, y\}\right),\left(e_{2},\{v, w, x, y\}\right)\right\} ; \\
& F_{20 E}=\left\{\left(e_{1},\{v, w, x, z\}\right),\left(e_{2},\{v, w, x, z\}\right)\right\} ; \\
& F_{21 E}=\left\{\left(e_{1},\{v, w, y, z\}\right),\left(e_{2},\{v, w, y, z\}\right)\right\} ; \\
& F_{22 E}=\left\{\left(e_{1},\{v, x, y, z\}\right),\left(e_{2},\{v, x, y, z\}\right)\right\} \text { and } \\
& F_{23 E}=\left\{\left(e_{1},\{w, x, y, z\}\right),\left(e_{2},\{w, x, y, z\}\right)\right\} .
\end{aligned}
$$

Then $\mu=\left\{\widetilde{\Phi}, \widetilde{X}, F_{i E}: i=1,2, \ldots, 23\right\}$ is a supra soft topology on $X$. It can be shown that $(X, \mu, E)$ is a supra soft $T_{3}$-space. On the other hand, the two soft sets $F^{c}{ }_{9 E}$ and $F^{c}{ }_{18 E}$ are two disjoint supra soft closed sets. Since every supra soft open set containing $F_{9 E}^{c}$ intersects any supra soft open set containing $F_{18 E}^{c}$, then $(X, \mu, E)$ is not a supra soft normal space. Hence, it is not a supra soft $T_{4}$-space.

Theorem 3.33. If $(X, \mu, E)$ is stable, then $(X, \mu, E)$ is a supra soft $T_{4}$-space if and only if the parametric supra topological space $\left(X, \mu_{e}\right)$ is supra $T_{4}$ for each $e \in E$.

Proof. Suppose that $(X, \mu, E)$ is a stable supra soft $T_{4}$-space. Then it follows from Proposition (3.9), that $\left(X, \mu_{e}\right)$ is supra soft $T_{1}$. Let $F$ and $H$ be two disjoint supra closed subsets of $\left(X, \mu_{e}\right)$. Since $(X, \mu, E)$ is stable, then there exist two disjoint supra soft closed subsets $U_{E}$ and $V_{E}$ of $(X, \mu, E)$ such that $U(e)=F$ and $V(e)=H$ for each $e \in E$. By hypothesis, there exist two disjoint supra soft open subsets $G_{E}$ and $W_{E}$ of $(X, \mu, E)$ such that $U_{E} \widetilde{\subseteq} G_{E}$ and $V_{E} \widetilde{\subseteq} W_{E}$. This implies that $G(e)$ and $W(e)$ are disjoint supra open subsets of $\left(X, \mu_{e}\right)$ containing $F$ and $H$, respectively. Thus, $\left(X, \mu_{e}\right)$ is supra normal. Hence, it is supra $T_{4}$.

To prove the converse, let $x \neq y \in X$. Since $\left(X, \mu_{e}\right)$ is supra $T_{4}$, then there are two supra open sets $G$ and $W$ containing $x$ and $y$, respectively, such that $x \notin W$ and $y \notin G$; and since $(X, \mu, E)$ is stable, then there are two supra soft open sets $M_{E}$ and $N_{E}$ such that $M(e)=G$ and $N(e)=W$ for each $e \in E$. This means that $(X, \mu, E)$ is supra soft $T_{1}$. Suppose that $U_{E}$ and $V_{E}$ are two non-null disjoint supra soft closed subsets of $(X, \mu, E)$. By the stability of $(X, \mu, E)$, it follows that $U(e)$ and $V(e)$ are two non-empty disjoint supra closed subsets of $\left(X, \mu_{e}\right)$ for each $e \in E$. Since $\left(X, \mu_{e}\right)$ is supra normal, then there are two disjoint supra open sets $G$ and $W$ containing $U(e)$ and $V(e)$, respectively. From Corollary (3.19), it follows that the soft sets $M_{E}$ and $N_{E}$, which are defined as 
$M(e)=G$ and $N(e)=W$ for each $e \in E$, are disjoint supra soft open sets containing $U_{E}$ and $V_{E}$, respectively. Thus, $(X, \mu, E)$ is supra soft normal. Hence, it is supra soft $T_{4}$.

Theorem 3.34. Every soft subspace $\left(Y, \mu_{Y}, E\right)$ of a supra soft $T_{i}$-space $(X, \mu, E)$ is a supra soft $T_{i}$-space, for $i=0,1,2,3$.

Proof. We prove the theorem in the case of $i=3$ and the other cases follow similar lines.

To prove that $\left(Y, \mu_{Y}, E\right)$ is supra soft $T_{1}$, let $x \neq y \in Y$. Since $(X, \mu, E)$ is supra soft $T_{1}$, then there exist supra soft open sets $G_{E}$ and $F_{E}$ such that $x \in G_{E}, y \notin G_{E}$ and $y \in F_{E}, x \notin F_{E}$. Therefore, $x \in U_{E}=\widetilde{Y} \widehat{\bigcap} G_{E}$ and $y \in V_{E}=\widetilde{Y} \widetilde{\cap} F_{E}$. Since $y \notin G_{E}$ and $x \notin F_{E}$, then $y \notin U_{E}$ and $x \notin V_{E}$. Thus, $\left(Y, \mu_{Y}, E\right)$ is supra soft $T_{1}$.

To prove the supra soft regularity of $\left(Y, \mu_{Y}, E\right)$, let $y \in Y$ and $L_{E}$ be a supra soft closed subset of $\left(Y, \mu_{Y}, E\right)$ such that $y \notin L_{E}$. Then there exists a supra soft closed subset $H_{E}$ of $(X, \mu, E)$ such that $L_{E}=\widetilde{Y} \widetilde{\cap} H_{E}$. Since $y \notin H_{E}$, then there exist disjoint supra soft open sets $G_{E}$ and $F_{E}$ such that $H_{E} \widetilde{\subseteq} G_{E}$ and $y \in F_{E}$. Now, we find that $L_{E} \widetilde{\subseteq} W_{1_{E}}=\widetilde{Y} \widetilde{\bigcap} G_{E}, y \in W_{2_{E}}=\widetilde{Y} \widetilde{\bigcap} F_{E}$ and $W_{1_{E}} \widetilde{\cap} W_{2_{E}}=\widetilde{\Phi}$. Thus, $\left(Y, \mu_{Y}, E\right)$ is supra soft regular. Hence, $\left(Y, \mu_{Y}, E\right)$ is supra soft $T_{3}$.

Theorem 3.35. Every supra soft closed subspace $\left(Y, \mu_{Y}, E\right)$ of a supra soft $T_{4}$-space $(X, \mu, E)$ is a supra soft $T_{4}$-space.

Proof. By the above theorem, a supra soft closed subspace $\left(Y, \mu_{Y}, E\right)$ of a supra soft $T_{4}$-space $(X, \mu, E)$ is supra soft $T_{1}$. To prove the supra soft normality of $\left(Y, \mu_{Y}, E\right)$, let $H_{1_{E}}$ and $H_{2_{E}}$ be two disjoint supra soft closed subsets of $\left(Y, \mu_{Y}, E\right)$. Since $\left(Y, \mu_{Y}, E\right)$ is a supra soft closed subspace of $(X, \mu, E)$, then $H_{1_{E}}$ and $H_{2_{E}}$ are two disjoint supra soft closed subsets of $(X, \mu, E)$ as well. Since $(X, \mu, E)$ is supra soft normal, then there are two disjoint supra soft open subsets $G_{1_{E}}$ and $G_{2_{E}}$ of $(X, \mu, E)$ such that $H_{1_{E}} \widetilde{\subseteq} G_{1_{E}}$ and $H_{2_{E}} \widetilde{\subseteq} G_{2_{E}}$. Obviously, $\widetilde{Y} \widetilde{\bigcap} G_{1_{E}}$ and $\widetilde{Y} \widetilde{\bigcap} G_{2_{E}}$ are disjoint supra soft open subsets of $\left(Y, \mu_{Y}, E\right)$ containing $H_{1_{E}}$ and $H_{2_{E}}$, respectively. This completes the proof.

Definition 3.36. Let $\left\{\left(X_{i}, \mu_{i}, A_{i}\right): i=1,2, \ldots, n\right\}$ be the collection of supra soft topological spaces. Then $\prod_{i=1}^{n} \mu_{i}=\left\{\prod_{i=1}^{n} G_{A_{i}}: G_{A_{i}} \in \mu_{i}\right\}$ defines a supra soft topology on $\prod_{i=1}^{n} X_{i}$ under a parameters set $\prod_{i=1}^{n} A_{i}$. We call $\prod_{i=1}^{n} \mu_{i}$ a finite product supra soft topology and $\left(\prod_{i=1}^{n} X_{i}, \prod_{i=1}^{n} \mu_{i}, \prod_{i=1}^{n} A_{i}\right)$ a finite product supra soft space.

Lemma 3.37. If $H_{A_{1} \times A_{2}}$ is a supra soft closed subset of a product supra soft space $\left(X \times Y, \mu_{1} \times \mu_{2}, A_{1} \times A_{2}\right)$, then $H_{A_{1} \times A_{2}}=\left[\left(G_{A_{1}}\right)^{c} \times \widetilde{Y}\right] \widetilde{\bigcup}\left[\widetilde{X} \times\left(U_{A_{2}}\right)^{c}\right]$ for some $G_{A_{1}} \in \mu_{1}$ and $U_{A_{2}} \in \mu_{2}$.

Theorem 3.38. The finite product of supra soft $T_{i}$-spaces $\left(X_{r}, \mu_{r}, A_{r}\right)$ is a supra soft $T_{i}$-space, for $i=0,1,2,3$.

Proof. We prove the theorem for two supra soft topological spaces in the case of $i=0,3$. The other cases follow similar lines.

(i) Consider two supra soft $T_{0}$-spaces $\left(X_{1}, \mu_{1}, A_{1}\right)$ and $\left(X_{2}, \mu_{2}, A_{2}\right)$ and let $\left(x_{1}, y_{1}\right) \neq\left(x_{2}, y_{2}\right)$ in $\left(X_{1} \times X_{2}, \mu_{1} \times\right.$ $\left.\mu_{2}, A_{1} \times A_{2}\right)$. Without lose of generality, let $x_{1} \neq x_{2}$. Then there exists a supra soft open subset $G_{A_{1}}$ of $\left(X_{1}, \mu_{1}, A_{1}\right)$ such that $x_{1} \in G_{A_{1}}$ and $x_{2} \notin G_{A_{1}}$ or $x_{2} \in G_{A_{1}}$ and $x_{1} \notin G_{A_{1}}$. Say, $x_{1} \in G_{A_{1}}$ and $x_{2} \notin G_{A_{1}}$. Therefore, $\left(x_{1}, y_{1}\right) \in G_{A_{1}} \times \widetilde{X_{2}}$ and $\left(x_{2}, y_{2}\right) \notin G_{A_{1}} \times \widetilde{X_{2}}$. Thus, $\left(X_{1} \times X_{2}, \mu_{1} \times \mu_{2}, A_{1} \times A_{2}\right)$ is a supra soft $T_{0}$-space.

(ii) Let $H_{A_{1} \times A_{2}}$ be a supra soft closed subset of a supra soft space $\left(X_{1} \times X_{2}, \mu_{1} \times \mu_{2}, A_{1} \times A_{2}\right)$. Then $H_{A_{1} \times A_{2}}=$ $\left[\left(G_{A_{1}}\right)^{c} \times \widetilde{X_{2}}\right] \cup \cup\left[\widetilde{X}_{1} \times\left(U_{A_{2}}\right)^{c}\right]$ for some $G_{A_{1}} \in \mu_{1}$ and $U_{A_{2}} \in \mu_{2}$. For every $(x, y) \notin H_{A_{1} \times A_{2}}$, we have $(x, y) \notin$ $\left(G_{A_{1}}\right)^{c} \times \widetilde{X_{2}}$ and $(x, y) \notin \widetilde{X_{1}} \times\left(U_{A_{2}}\right)^{c}$. So $x \notin\left(G_{A_{1}}\right)^{c}$ and $y \notin\left(U_{A_{2}}\right)^{c}$. Since $\left(X_{1}, \mu_{1}, A_{1}\right)$ and $\left(X_{2}, \mu_{2}, A_{2}\right)$ are supra soft regular, then there exist disjoint supra soft open sets $F_{1_{A_{1}}}$ and $F_{2_{A_{1}}}$ containing $x$ and $\left(G_{A_{1}}\right)^{c}$, respectively, and there exist disjoint supra soft open sets $F_{3_{A_{2}}}$ and $F_{4_{A_{2}}}$ containing $y$ and $\left(U_{A_{2}}\right)^{c}$, respectively. Thus, $H_{A_{1} \times A_{2}} \widetilde{\subseteq}\left[F_{2_{A_{1}}} \times \widetilde{X_{2}}\right] \widetilde{\bigcup}\left[\widetilde{X_{1}} \times F_{4_{A_{2}}}\right]$ and $(x, y) \in\left[F_{1_{A_{1}}} \times F_{3_{A_{2}}}\right]$. Since $\left[F_{1_{A_{1}}} \times F_{3_{A_{2}}}\right] \widetilde{\cap}\left\{\left[F_{2_{A_{1}}} \times \widetilde{X_{2}}\right] \widetilde{\bigcup}\left[\widetilde{X_{1}} \times F_{4_{A_{2}}}\right]\right\}=$ $\widetilde{\Phi_{A_{1} \times A_{2}}}$, then $\left(X_{1} \times X_{2}, \mu_{1} \times \mu_{2}, A_{1} \times A_{2}\right)$ is supra soft regular. From (i) above and Theorem (3.23), the desired result is proved. 
Remark 3.39. It is well known that a supra soft topological space $(X, \mu, E)$ is supra topological space if a set of parameters $E$ is a singleton. We also know, from general topology, that a Sorgenfrey Line space is normal, however, the product of two Sorgenfrey Line spaces is not normal. This explains why supra soft $T_{4}$-spaces are excluded from the above theorem.

Definition 3.40. A soft mapping $f_{\phi}:(X, \mu, A) \rightarrow(Y, \theta, B)$ is said to be:

(i) Soft $S^{\star}$-continuous if the inverse image of each supra soft open subset of $(Y, \theta, B)$ is a supra soft open subset of $(X, \mu, A)$.

(ii) Soft $S^{\star}$-open (resp. Soft $S^{\star}$-closed) if the image of each supra soft open (resp. supra soft closed) subset of $(X, \mu, A)$ is a supra soft open (resp. supra soft closed) subset of $(Y, \theta, B)$.

(iii) Soft $S^{\star}$-homeomorphism if it is bijective, soft $S^{\star}$-continuous and soft $S^{\star}$-open.

Definition 3.41. A property is said to be a supra soft topological property if the property is preserved by a soft $S^{\star}$-homeomorphism mapping.

Proposition 3.42. Let $f_{\phi}:(X, \mu, A) \rightarrow(Y, \theta, B)$ be a soft $S^{\star}$-continuous mapping such that $f$ is an injective mapping. If $(Y, \theta, B)$ is supra soft $T_{i}$, then $(X, \mu, A)$ is supra soft $T_{i}$ for $i=0,1,2$.

Proof. We only prove the proposition for $i=2$.

Consider two distinct points $a$ and $b$ in $X$. By injectivity of $f$, there are two distinct points $x$ and $y$ in $Y$ such that $f(a)=x$ and $f(b)=y$. Since $(Y, \theta, B)$ is a supra soft $T_{2}$-space, then there are two disjoint supra soft open sets $G_{B}$ and $F_{B}$ such that $x \in G_{B}$ and $y \in F_{B}$. From Proposition (2.16), we obtain $a \in f_{\phi}^{-1}\left(G_{B}\right)$ and $b \in f_{\phi}^{-1}\left(F_{B}\right)$. Obviously, $f_{\phi}^{-1}\left(G_{B}\right) \widetilde{\bigcap} f_{\phi}^{-1}\left(F_{B}\right)=\widetilde{\Phi_{A}}$. Thus, $(X, \mu, A)$ is a supra soft $T_{2}$-space.

For the sake of brevity, we omit the proofs of the following four results.

Proposition 3.43. Let $f_{\phi}:(X, \mu, A) \rightarrow(Y, \theta, B)$ be a bijective soft $S^{\star}$-continuous mapping. If $(Y, \theta, B)$ is supra soft $T_{i}$, then $(X, \mu, A)$ is supra soft $T_{i}$ for $i=0,1,2,3,4$.

Proposition 3.44. Let $f_{\phi}:(X, \mu, A) \rightarrow(Y, \theta, B)$ be a bijective soft $S^{\star}$-open mapping. If $(X, \mu, A)$ is supra soft $T_{i}$, then $(Y, \theta, B)$ is supra soft $T_{i}$ for $i=0,1,2,3,4$.

Proposition 3.45. Let $f_{\phi}:(X, \mu, A) \rightarrow(Y, \theta, B)$ be a soft $S^{\star}$-homeomorphism mapping. Then $(X, \mu, A)$ is supra soft $T_{i}$ if and only if $(Y, \theta, B)$ is supra soft $T_{i}$ for $i=0,1,2,3,4$.

Corollary 3.46. The property of being supra soft $T_{i}$ is a supra soft topological property, for $i=0,1,2,3,4$.

\section{Supra p-soft $T_{i}$-spaces $(i=0,1,2,3,4)$}

The main purpose of this section is to define and study the concepts of supra p-soft $T_{i}$-spaces $(i=0,1,2,3,4)$ by using natural belong and total non belong relations. With the help of examples, the relationships between them, as well as between them and supra soft $T_{i}$-spaces introduced in the previous section are illustrated.

Definition 4.1. A supra soft topological space $(X, \mu, E)$ is said to be:

(i) a supra $p$-soft $T_{0}$-space iffor every $x \neq y \in X$, there exists a supra soft open set $G_{E}$ such that $x \in G_{E}, y \notin G_{E}$ or $y \in G_{E}, x \notin G_{E}$.

(ii) a supra $p$-soft $T_{1}$-space if for every $x \neq y \in X$, there exist supra soft open sets $G_{E}$ and $F_{E}$ such that $x \in$ $G_{E}, y \notin G_{E}$ and $y \in F_{E}, x \notin F_{E}$. 
(iii) a supra $p$-soft $T_{2}$-space if for every $x \neq y \in X$, there exist two disjoint supra soft open sets $G_{E}$ and $F_{E}$ such that $x \in G_{E}, y \notin G_{E}$ and $y \in F_{E}, x \notin F_{E}$.

Remark 4.2. For any two disjoint soft sets $G_{E}$ and $F_{E}$ such that $x \in G_{E}$ and $y \in F_{E}$, we find that $y \notin G_{E}$ and $x \notin F_{E}$ if and only if $y \notin G_{E}$ and $x \notin F_{E}$. So the definitions of supra $p$-soft $T_{2}$-spaces and supra soft $T_{2}$-spaces are equivalent. Hence, the properties of a supra soft $T_{2}$-spaces are still valid for a supra $p$-soft $T_{2}$-spaces.

Proposition 4.3. Every supra $p$-soft $T_{i}$-space is a supra soft $T_{i}$-space, for $i=0,1$.

Proof. It follows from the fact that a total non belong relation $\notin$ implies a non belong relation $\notin$.

The next example points out that the converse of the above proposition is not true.

Example 4.4. Assume that $\left(X, \mu_{2}, E\right)$ is the same as in Example (3.3). We mentioned that $\left(X, \mu_{2}, E\right)$ is supra soft $T_{1}$. On the other hand, $x \neq y$ and there does not exist a supra soft open subset of $\left(X, \mu_{2}, E\right)$ which contains one of the points $x$ or $y$ such that the other point does not totally belong to it. $S o\left(X, \mu_{2}, E\right)$ is not supra $p$-soft $T_{0}$.

Proposition 4.5. If $(X, \mu, E)$ is a supra $p$-soft $T_{i}$-space, then a parametric supra topological space $\left(X, \mu_{e}\right)$ is supra $T_{i}$ for $i=0,1,2$.

Proof. In the case of $i=2$, the proof follows from Proposition (3.5) and Remark (4.2).

In the case of $i=1$, let $x \neq y \in X$. Since $(X, \mu, E)$ is a supra soft $T_{1}$-space, then there exist two supra soft open sets $F_{E}$ and $G_{E}$ containing $x$ and $y$, respectively, such that $y \notin F_{E}$ and $x \notin G_{E}$. Thus, $F(e)$ and $G(e)$ are non-empty proper supra soft open subsets of $\left(X, \mu_{e}\right)$ containing $x$ and $y$, respectively, such that $y \notin F(e)$ and $x \notin G(e)$. This shows that $\left(X, \mu_{e}\right)$ is a supra $T_{2}$-space.

One can similarly prove the proposition in the case of $i=0$.

Example (3.6) obviously shows that the converse of the above proposition does not hold.

We discuss in the following results some properties related to a p-soft $T_{0}$-space.

Lemma 4.6. Let $H_{E}$ be a soft subset of $(X, \mu, E)$ and $x \in X$. Then $x \notin C l_{\mu}\left(H_{E}\right)$ if and only if there exists a supra soft open set $F_{E}$ containing $x$ such that $H_{E} \widetilde{\bigcap} F_{E}=\widetilde{\Phi}$.

Proof. $\Rightarrow$ : Let $x \notin C l_{\mu}\left(H_{E}\right)$. Then $x \in\left(C l_{\mu}\left(H_{E}\right)\right)^{c}=F_{E}$. Thus, $H_{E} \widetilde{\bigcap} F_{E}=\widetilde{\Phi}$.

$\Leftarrow$ : Let $F_{E}$ be a supra soft open set such that $x \in F_{E}$ and $H_{E} \widetilde{\cap} F_{E}=\widetilde{\Phi}$. Then $H_{E} \widetilde{\subseteq} F_{E}^{c}$. Therefore, $C l_{\mu}\left(H_{E}\right) \subseteq F_{E}^{c}$. Since $x \notin F_{E}^{c}$, then $x \notin C l_{\mu}\left(H_{E}\right)$.

Theorem 4.7. If $(X, \mu, E)$ is a supra $p$-soft $T_{0}$-space, then $C_{\mu}\left(x_{E}\right) \neq C l_{\mu}\left(y_{E}\right)$ for every $x \neq y \in X$.

Proof. Let $x, y$ be two distinct points in a supra p-soft $T_{0}$-space. Then there is a supra soft open set $G_{E}$ such that $x \in G_{E}$ and $y \notin G_{E}$ or $y \in G_{E}$ and $x \notin G_{E}$. Say, $x \in G_{E}$ and $y \notin G_{E}$. Now, $y_{E} \widetilde{\bigcap} G_{E}=\widetilde{\Phi}$. So, by the above lemma, $x \notin C l_{\mu}\left(y_{E}\right)$. But $x \in C l_{\mu}\left(x_{E}\right)$. This shows that $C l_{\mu}\left(x_{E}\right) \neq C l_{\mu}\left(y_{E}\right)$.

Corollary 4.8. If $(X, \mu, E)$ is a supra $p$-soft $T_{0}$-space, then $C l_{\mu}\left(P_{\alpha}^{x}\right) \neq C l_{\mu}\left(P_{\beta}^{y}\right)$ for each $x \neq y \in X$ and $\alpha, \beta \in E$.

Proof. From the proof of Theorem(4.7), we have $x \notin C l_{\mu}\left(y_{E}\right)$ or $y \notin C l_{\mu}\left(x_{E}\right)$ for each $x \neq y$. Say, $x \notin C l_{\mu}\left(y_{E}\right)$. As $C l_{\mu}\left(P_{\beta}^{y}\right) \widetilde{\subseteq} C l_{\mu}\left(y_{E}\right)$, then $x \notin C l_{\mu}\left(P_{\beta}^{y}\right)$. Obviously, $x \Subset C l_{\mu}\left(P_{\alpha}^{x}\right)$. Hence, $C l_{\mu}\left(P_{\alpha}^{x}\right) \neq C l_{\mu}\left(P_{\beta}^{y}\right)$, as required.

It can be seen from the next example that the converse of the above theorem fails.

Example 4.9. Assume that $\left(X, \mu_{1}, E\right)$ is the same as in Example (3.3). Then $\mathrm{Cl}_{\mu}\left(x_{E}\right) \neq C l_{\mu}\left(y_{E}\right)$. On the other hand, we show in Example (4.4) that $\left(X, \mu_{1}, E\right)$ is not a supra p-soft $T_{0}$-space.

In the following results, we characterize a supra p-soft $T_{1}$-space and investigate some of its features. 
Theorem 4.10. $(X, \mu, E)$ is a supra $p$-soft $T_{1}$-space if and only if $x_{E}$ is a supra soft closed set for all $x \in X$.

Proof. Necessity: For each $y_{i} \in X \backslash\{x\}$, there is a supra soft open set $G_{i_{E}}$ such that $y_{i} \in G_{i_{E}}$ and $x \notin G_{i_{E}}$. Therefore, $X \backslash\{x\}=\bigcup_{i \in I} G_{i}(e)$ and $x \notin \bigcup_{i \in I} G_{i}(e)$ for each $e \in E$. Thus, $\widetilde{\bigcup}_{i \in I} G_{i_{E}}=\widetilde{X \backslash\{x\}}$ is a supra soft open set. Hence, $x_{E}$ is supra soft closed.

Sufficiency: For each $x \neq y$, we have $x_{E}$ and $y_{E}$ are supra soft closed sets. Now, $\in\left(x_{E}\right)^{c}$ and $\left(y_{E}\right)^{c}$ are two supra soft open sets containing $y$ and $x$, respectively. Since $x \notin(X \backslash\{x\})_{E}$ and $y \notin(X \backslash\{y\})_{E}$, then $(X, \mu, E)$ is a supra p-soft $T_{1}$-space.

Corollary 4.11. A finite supra soft topological space $(X, \mu, E)$ with $|X| \geq 2$ contains at least $|X|+2$ supra soft open sets.

Proof. Let $X$ be the universe set with $|X| \geq 2$ and $E$ be a set of parameters. Then the collection $\theta=\left\{\widetilde{\Phi}, \widetilde{X}, G_{i E}\right.$ such that $G_{i}(e)=X \backslash\left\{x_{i}\right\}$, for each $\left.e \in E: i=1,2, \ldots,|X|\right\}$ forms a supra soft topology on $X$. The number of all non-null proper supra soft open subsets of $(X, \theta, E)$ is $\left(\begin{array}{c}|X| \\ |X|-1\end{array}\right)=|X|$. So $|\theta|=|X|+2$. Take arbitrary distinct points $x_{i}, x_{j} \in X$. The soft sets $F_{E}$ and $H_{E}$ defined as follows:

$$
\begin{aligned}
& F_{E}=\left\{\left(e, X \backslash\left\{x_{j}\right\}\right): e \in E ; x_{j} \in X\right\} \text { and } \\
& H_{E}=\left\{\left(e_{1}, X \backslash\left\{x_{i}\right\}\right): e \in E ; x_{i} \in X\right\}
\end{aligned}
$$

are supra soft open sets containing $x_{i}$ and $x_{j}$, respectively, such that $x_{i} \notin H_{E}$ and $x_{j} \notin F_{E}$. This proves that $(X, \theta, E)$ is a supra soft $T_{1}$-space. To prove that it is the smallest supra soft $T_{1}$, remove any non-null proper supra soft open set. Say, $G_{1 E}$. Then $x_{1_{E}}$ is not a supra soft closed set. This contradicts that $(X, \theta, E)$ is supra soft $T_{1}$. Hence, the desired result is proved.

Proposition 4.12. If $(X, \mu, E)$ is a supra $p$-soft $T_{1}$-space, then $x_{E}=\widetilde{\bigcap}\left\{G_{E}: x \in G_{E} \in \mu\right\}$ for all $x \in X$.

Proof. For each $y \in X$ such that $x \neq y$, there exists a supra soft open set $G_{E}$ such that $x \in G_{E}$ and $y \notin G_{E}$. So $x \in \widetilde{\bigcap} G_{E}$ and $y \notin \widetilde{\bigcap} G_{E}$. Hence, the desired result is proved.

Definition 4.13. The collection $\Lambda$ of soft sets over $X$ with a parameters set $E$ is called enriched if it contains all soft sets $G_{E}$ which are defined as $G(e)=X$ or $\emptyset$ for each $e \in E$.

Theorem 4.14. If $(X, \mu, E)$ is an enriched supra $p$-soft $T_{1}$-space, then $P_{e}^{X}$ is a supra soft closed set for all $P_{e}^{X} \in \widetilde{X}$.

Proof. From Theorem (4.10), we get $\widetilde{X \backslash\{x\}}$ is supra soft open. As $(X, \mu, E)$ is enriched, then a soft set $H_{E}$,

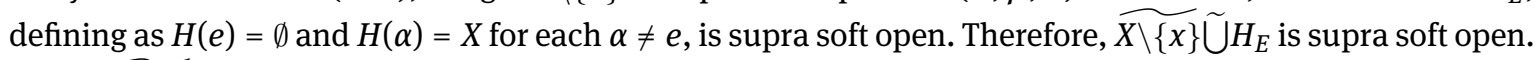
Thus, $\left(\widetilde{X \backslash\{x\}} \widetilde{\cup} H_{E}\right)^{c}=P_{e}^{X}$ is a supra soft closed set.

Corollary 4.15. If $(X, \mu, E)$ is an enriched supra p-soft $T_{1}$-space, then the intersection of all supra soft open sets containing $U_{E}$ is exactly $U_{E}$ for each $U_{E} \widetilde{\subseteq} \widetilde{X}$.

Proof. Let $U_{E}$ be a soft subset of $\widetilde{X}$ and $P_{e}^{X} \in U_{E}^{c}$. Since $P_{e}^{x}$ is supra soft closed, then $\widetilde{X} \backslash P_{e}^{x}$ is a supra soft open set containing $U_{E}$. By doing similarly for each $P_{e}^{X} \in U_{E}^{c}$, the corollary holds.

The following two results demonstrate that the condition of supra soft regularity guarantees the equivalence between the introduced supra soft separation axioms for $i=0,1,2$.

Theorem 4.16. Let $(X, \mu, E)$ be a supra soft regular space. Then $(X, \mu, E)$ is supra $p$-soft $T_{2}$ if and only if it is supra soft $T_{0}$.

Proof. The proof of the "if" part follows directly from Proposition(3.2) and Remark(4.2).

The proof of the "only if" part follows directly from Theorem(3.23) and Remark(4.2).

Corollary 4.17. Let $(X, \mu, E)$ be a supra soft regular space. Then the following five statements are equivalent. 
(i) $(X, \mu, E)$ is supra soft $T_{1}$.

(ii) $(X, \mu, E)$ is supra soft $T_{0}$.

(iii) $(X, \mu, E)$ is supra p-soft $T_{2}$.

(iv) $(X, \mu, E)$ is supra p-soft $T_{1}$.

(v) $(X, \mu, E)$ is supra p-soft $T_{0}$.

Remark 4.18. In the definition of supra soft regular space in the previous section, we point out, in Corollary (3.18), that every supra soft open or supra soft closed subset of a supra soft regular space must be stable. To avoid this strict condition, we introduce a concept of a supra p-soft regular space by using a total non belong relation instead of a natural non belong relation.

Definition 4.19. A supra soft topological space $(X, \mu, E)$ is said to be supra $p$-soft regular iffor every supra soft closed set $H_{E}$ and $x \in X$ such that $x \notin H_{E}$, there exist disjoint supra soft open sets $G_{E}$ and $F_{E}$ such that $H_{E} \widetilde{\simeq} G_{E}$ and $x \in F_{E}$.

Proposition 4.20. Every supra soft regular space is supra p-soft regular.

Proof. The proof follows from the fact total non belong relation $\notin$ obviously implies natural non belong relation $\notin$.

The next example elucidates that the converse of the above proposition fails.

Example 4.21. The supra soft topological space $(X, \mu, E)$ which given in Example (3.27) is supra p-soft regular, because for any supra soft closed set and each point does not totally belong to it, there exist two disjoint supra soft open sets, one of them contains a supra soft closed set and the other contains a point. On the other hand, we elucidate in Example (3.27) that $(X, \mu, E)$ is not supra soft regular.

Theorem 4.22. $(X, \mu, E)$ is supra $p$-soft regular if and only if for each $x \in X$ and every supra soft open set $F_{E}$ containing $x$, there exists a supra soft open set $G_{E}$ such that $x \in G_{E} \widetilde{\widetilde{\subseteq}} C l_{\mu}\left(G_{E}\right) \widetilde{\widetilde{\subseteq}} F_{E}$.

Proof. To prove the necessary part, let $x \in X$ and $F_{E}$ be a supra soft open set containing $x$. Then $F_{E}^{c}$ is supra soft closed and $x \notin F_{E}^{c}$. Therefore, there are disjoint supra soft open sets $W_{E}$ and $G_{E}$ such that $F_{E}^{c} \widetilde{\subseteq} W_{E}$ and $x \in G_{E}$. So $G_{E} \widetilde{\simeq} W_{E}^{c} \widetilde{\simeq} F_{E}$. Thus, $C l_{\mu}\left(G_{E}\right) \widetilde{\widetilde{C}} W_{E}^{c} \widetilde{\simeq} F_{E}$.

To prove the sufficient part, let $F_{E}^{c}$ be a supra soft closed set. Then for each $x \notin F_{E}^{c}$, we have $x \in F_{E}$. By hypothesis, there is a supra soft open set $G_{E}$ containing $x$ such that $C l_{\mu}\left(G_{E}\right) \widetilde{\widetilde{\subseteq}} F_{E}$. Therefore, $F_{E}^{c} \widetilde{\widetilde{\subseteq}}\left(C l_{\mu}\left(G_{E}\right)\right)^{c}$ and $G_{E} \widetilde{\bigcap}\left(C l_{\mu}\left(G_{E}\right)\right)^{c}=\widetilde{\Phi}$. Thus, $(X, \mu, E)$ is supra p-soft regular, as required.

Theorem 4.23. For any supra p-soft regular space $(X, \mu, E)$, the following three statements are equivalent:

(i) $(X, \mu, E)$ is a supra $p$-soft $T_{2}$-space.

(ii) $(X, \mu, E)$ is a supra $p$-soft $T_{1}$-space.

(iii) $(X, \mu, E)$ is a supra $p$-soft $T_{0}$-space.

Proof. Obviously, (i) $\rightarrow$ (ii) $\rightarrow$ (iii).

(iii) $\rightarrow$ (i): Let $x \neq y \in X$ and $(X, \mu, E)$ be a supra p-soft $T_{0}$-space. Then there exists a supra soft open set $G_{E}$ such that $x \in G_{E}$ and $y \notin G_{E}$ or $y \in G_{E}$ and $x \notin G_{E}$. Say, $x \in G_{E}$ and $y \notin G_{E}$. So $x \notin G_{E}^{c}$ and $y \in G_{E}^{c}$. Since $(X, \mu, E)$ is supra p-soft regular, then there exist two disjoint supra soft open sets $W_{1_{E}}$ and $W_{2_{E}}$ such that $x \in W_{1_{E}}$ and $y \in G_{E}^{c} \widetilde{\simeq} W_{2_{E}}$. This finishes the proof.

Definition 4.24. The collection $\Lambda$ of supra soft open subsets of $(X, \mu, E)$ is called a supra soft basis for $\widetilde{X}$ if every supra soft open set can be expressed as a soft union of members of $\Lambda$. 
Proposition 4.25. The collection $\Lambda$ is a supra soft basis for $(X, \mu, E)$ if and only if for each supra soft open set $G_{E}$ such that $x \Subset G_{E}$, there is a supra soft open set $H_{E}$ such that $x \Subset H_{E} \widetilde{\subseteq} G_{E}$.

Proof. Straightforward.

Theorem 4.26. If $(X, \mu, E)$ has a supra soft basis of supra soft clopen sets, then $(X, \mu, E)$ is supra p-soft regular.

Proof. Let $\Lambda$ be a supra soft basis for $\widetilde{X}$ consisting of supra soft clopen sets. Take an arbitrary point $x \in X$ and a supra soft closed set $H_{E}$ such that $x \notin H_{E}$. Then $x \in H_{E}^{c}$ which is a supra soft open set, and therefore there exists a supra soft clopen set $F_{E}$ in $\Lambda$ such that $x \in F_{E} \widetilde{\widetilde{\subseteq}} H_{E}^{c}$. Obviously, $H_{E} \widetilde{\widetilde{\subseteq}} F_{E}^{c}$. Thus, $F_{E}$ and $F_{E}^{c}$ are supra soft open sets separating $x$ and $H_{E}$. Hence, $(X, \mu, E)$ is supra p-soft regular, as required.

Definition 4.27. A supra soft topological space $(X, \mu, E)$ is said to be:

(i) a supra $p$-soft $T_{3}$-space if it is both supra $p$-soft regular and supra $p$-soft $T_{1}$.

(ii) a supra $p$-soft $T_{4}$-space if it is both supra soft normal and supra $p$-soft $T_{1}$.

Proposition 4.28. Every supra soft $T_{3}$-space is a supra -soft $T_{3}$-space.

Proof. One can obtain the proof from Corollary (4.17) and Proposition (4.20).

It can be seen from Example (3.27) that the converse of the above proposition need not be true in general.

Proposition 4.29. Every supra $p$-soft $T_{4}$-space is a supra soft $T_{4}$-space.

Proof. Straightforward.

To show that the converse of the above proposition fails, we give the next example.

Example 4.30. Let $E=\left\{e_{1}, e_{2}, e_{3}\right\}$ and $\mu=\left\{\widetilde{\Phi}, \widetilde{X}, G_{i_{E}}: i=1,2, \ldots, 5\right\}$ be a supra soft topology on $X=\{x, y\}$, where

$$
\begin{aligned}
& G_{1_{E}}=\left\{\left(e_{1}, X\right),\left(e_{2},\{x\}\right),\left(e_{3}, X\right)\right\} ; \\
& G_{2_{E}}=\left\{\left(e_{1}, X\right),\left(e_{2},\{y\}\right),\left(e_{3}, X\right)\right\} ; \\
& G_{3_{E}}=\left\{\left(e_{1}, \emptyset\right),\left(e_{2},\{x\}\right),\left(e_{3}, \emptyset\right)\right\} ; \\
& G_{4_{E}}=\left\{\left(e_{1}, \emptyset\right),\left(e_{2},\{y\}\right),\left(e_{3}, \emptyset\right)\right\} \text { and } \\
& G_{5_{E}}=\left\{\left(e_{1}, \emptyset\right),\left(e_{2}, X\right),\left(e_{3}, \emptyset\right)\right\} .
\end{aligned}
$$

Then $(X, \mu, E)$ is a supra soft $T_{4}$-space. On the other hand, there does not exist a supra soft open set containing $y$ such that $x$ does not totally belong to it. $S o(X, \mu, E)$ is not a supra $p$-soft $T_{1}$-space, hence, it is not a supra -soft $T_{4}$-space.

Now, we elucidate a relationship between supra p-soft $T_{i}$-spaces and deduce some results which associate them with some soft topological notions such as supra soft subspaces and product supra soft spaces.

Proposition 4.31. Every supra $p$-soft $T_{i}$-space is supra $p$-soft $T_{i-1}$, for $i=1,2,3,4$.

Proof. We prove the proposition in the case of $i=3$, 4. The other cases follow similar lines.

For $i=3$, let $x, y$ be two distinct points in a supra p-soft $T_{3}$-space $(X, \mu, E)$. Then $(X, \mu, E)$ is supra p-soft $T_{1}$. So $x_{E}$ is supra soft closed. Since $y \notin X_{E}$ and $(X, \mu, E)$ is supra p-soft regular, then there are disjoint supra soft open sets $G_{E}$ and $F_{E}$ such that $x_{E} \widetilde{\subseteq} G_{E}$ and $y \in F_{E}$. Therefore, $(X, \mu, E)$ is a supra p-soft $T_{2}$-space.

For $i=4$, let $x \in X$ and $H_{E}$ be a supra soft closed set such that $x \notin H_{E}$. Since $(X, \mu, E)$ is supra p-soft $T_{1}$, then $x_{E}$ is supra soft closed. Since $x_{E} \widetilde{\bigcap} H_{E}=\widetilde{\Phi}$ and $(X, \mu, E)$ is supra soft normal, then there are disjoint supra soft open sets $G_{E}$ and $F_{E}$ such that $H_{E} \widetilde{\subseteq} G_{E}$ and $x_{E} \widetilde{\subseteq} F_{E}$. Thus, $(X, \mu, E)$ is supra soft regular. Hence, it is a supra p-soft $T_{3}$-space. 
The following examples and remark show that the converse of the above proposition need not be true in general.

Example 4.32. Let $\mu=\left\{\widetilde{\Phi}, \widetilde{X},\left\{\left(e_{1},\{x\}\right),\left(e_{2},\{x\}\right)\right\}\right\}$ be a supra soft topology on $X=\{x, y\}$ under a parameters set $E=\left\{e_{1}, e_{2}\right\}$. Obviously, $(X, \mu, E)$ is a supra p-soft $T_{0}$-space, but it is not a supra p-soft $T_{1}$-space.

Example 4.33. Assume that $X=\{x, y, z\}$ and $E=\left\{e_{1}, e_{2}\right\}$; and let the soft sets $\left\{F_{i E}: i=1,2, \ldots, 8\right\}$ over $X$ be given as follows:

$$
\begin{aligned}
& F_{1 E}=\left\{\left(e_{1},\{x\}\right),\left(e_{2},\{x\}\right)\right\} ; \\
& F_{2 E}=\left\{\left(e_{1},\{y\}\right),\left(e_{2},\{y\}\right)\right\} ; \\
& F_{3 E}=\left\{\left(e_{1},\{x, y\}\right),\left(e_{2},\{x, y\}\right)\right\} ; \\
& F_{4 E}=\left\{\left(e_{1},\{x, z\}\right),\left(e_{2},\{x, z\}\right)\right\} ; \\
& F_{5 E}=\left\{\left(e_{1},\{y, z\}\right),\left(e_{2},\{y, z\}\right)\right\} ; \\
& F_{6 E}=\left\{\left(e_{1},\{z\}\right),\left(e_{2}, X\right)\right\} ; \\
& F_{7 E}=\left\{\left(e_{1},\{x, z\}\right),\left(e_{2}, X\right)\right\} \text { and } \\
& F_{8 E}=\left\{\left(e_{1},\{y, z\}\right),\left(e_{2}, X\right)\right\} .
\end{aligned}
$$

Then $\mu=\left\{\widetilde{\Phi}, \widetilde{X}, F_{i E}: i=1,2, \ldots, 8\right\}$ is a supra soft topology on $X$. Obviously, $(X, \mu, E)$ is a supra p-soft $T_{2}$-space. On the other hand, $F_{6 E}^{c}$ is a supra soft closed set such that $z \notin F_{6 E}^{c}$. Since there are no two disjoint supra soft open sets such that one of them contains $z$ and the other contains $F_{6 E}^{c}$, then $(X, \mu, E)$ is not a supra p-soft regular space. Hence, it is not a supra $p$-soft $T_{3}$-space.

Remark 4.34. The supra soft topological space given in Example (3.14) is supra $p$-soft $T_{1}$, but is not supra psoft $T_{2}$. Also, the supra soft topological space given in Example (3.32) is supra p-soft $T_{3}$, but it is not supra p-soft $T_{4}$.

Theorem 4.35. The finite product of supra p-soft $T_{i}$-spaces $\left(X_{r}, \mu_{r}, A_{r}\right)$ is a supra p-soft $T_{i}$-space, for $i=$ $0,1,2,3$.

Proof. We prove the theorem for two supra soft topological spaces in the case of $i=0,3$. The other cases follow similar lines.

(i) Consider two supra p-soft $T_{0}$-spaces $\left(X_{1}, \mu_{1}, A_{1}\right)$ and $\left(X_{2}, \mu_{2}, A_{2}\right)$ and let $\left(x_{1}, y_{1}\right) \neq\left(x_{2}, y_{2}\right)$ in $\left(X_{1} \times\right.$ $\left.X_{2}, \mu_{1} \times \mu_{2}, A_{1} \times A_{2}\right)$. Without loss of generality, let $x_{1} \neq x_{2}$. Then there exists a supra soft open subset $G_{A_{1}}$ of $\left(X_{1}, \mu_{1}, A_{1}\right)$ such that $x_{1} \in G_{A_{1}}$ and $x_{2} \notin G_{A_{1}}$ or $x_{2} \in G_{A_{1}}$ and $x_{1} \notin G_{A_{1}}$. Say, $x_{1} \in G_{A_{1}}$ and $x_{2} \notin G_{A_{1}}$. Therefore, $\left(x_{1}, y_{1}\right) \in G_{A_{1}} \times \widetilde{X_{2}}$ and $\left(x_{2}, y_{2}\right) \notin G_{A_{1}} \times \widetilde{X_{2}}$. Thus, $\left(X_{1} \times X_{2}, \mu_{1} \times \mu_{2}, A_{1} \times A_{2}\right)$ is a supra p-soft $T_{0}$-space.

(ii) Let $H_{A_{1} \times A_{2}}$ be a supra soft closed subset of a supra soft space $\left(X_{1} \times X_{2}, \mu_{1} \times \mu_{2}, A_{1} \times A_{2}\right)$. Then $H_{A_{1} \times A_{2}}=$ $\left[\left(G_{A_{1}}\right)^{c} \times \widetilde{X_{2}}\right] \cup\left[\widetilde{X_{1}} \times\left(U_{A_{2}}\right)^{c}\right]$ for some $G_{A_{1}} \in \mu_{1}$ and $U_{A_{2}} \in \mu_{2}$. For every $(x, y) \notin H_{A_{1} \times A_{2}}$, we have $(x, y) \notin$ $\left(G_{A_{1}}\right)^{c} \times \widetilde{X_{2}}$ and $(x, y) \notin \widetilde{X_{1}} \times\left(U_{A_{2}}\right)^{c}$. So $x \notin\left(G_{A_{1}}\right)^{c}$ and $y \notin\left(U_{A_{2}}\right)^{c}$. Since $\left(X_{1}, \mu_{1}, A_{1}\right)$ and $\left(X_{2}, \mu_{2}, A_{2}\right)$ are supra p-soft regular, then there exist disjoint supra soft open sets $F_{1_{A_{1}}}$ and $F_{2_{A_{1}}}$ containing $x$ and $\left(G_{A_{1}}\right)^{c}$, respectively, and there exist disjoint supra soft open sets $F_{3_{A_{2}}}$ and $F_{4_{A_{2}}}$ containing $y$ and $\left(U_{A_{2}}\right)^{C}$, respectively. Thus, $H_{A_{1} \times A_{2}} \widetilde{\widetilde{C}}\left[F_{2_{A_{1}}} \times \widetilde{X_{2}}\right] \widetilde{\bigcup}\left[\widetilde{X_{1}} \times F_{4_{A_{2}}}\right],(x, y) \in\left[F_{1_{A_{1}}} \times F_{3_{A_{2}}}\right]$ and $\left[F_{1_{A_{1}}} \times F_{3_{A_{2}}}\right] \widetilde{\bigcap}\left\{\left[F_{2_{A_{1}}} \times \widetilde{X_{2}}\right] \widetilde{\bigcup}\left[\widetilde{X_{1}} \times F_{4_{A_{2}}}\right]\right\}=\widetilde{\Phi_{A_{1} \times A_{2}}}$. From (i) above and Theorem (4.23), the desired result is proved.

Remark 4.36. Since the two relations $\notin$ and $\notin$ are equivalent if $E$ is a singleton, then Remark (3.39) explains the excluding of supra $p$-soft $T_{4}$-spaces from the above theorem.

Theorem 4.37. Every soft subspace $\left(Y, \mu_{Y}, E\right)$ of a supra p-soft $T_{i}$-space $(X, \mu, E)$ is a supra $p$-soft $T_{i}$-space, for $i=0,1,2,3$. 
Proof. We prove the theorem in the case of $i=3$ and the other cases follow similar lines.

To prove that $\left(Y, \mu_{Y}, E\right)$ is supra p-soft $T_{1}$, let $x \neq y \in Y$. Since $(X, \mu, E)$ is a supra p-soft $T_{1}$-space, then there exist supra soft open sets $G_{E}$ and $F_{E}$ such that $x \in G_{E}, y \notin G_{E}, y \in F_{E}$, and $x \notin F_{E}$. Therefore, $x \in U_{E}=\widetilde{Y} \widetilde{\bigcap} G_{E}$ and $y \in V_{E}=\widetilde{Y} \widetilde{\bigcap} F_{E}$. Since $y \notin G_{E}$ and $x \notin F_{E}$, then $y \notin U_{E}$ and $x \notin V_{E}$. Thus, $\left(Y, \mu_{Y}, E\right)$ is supra p-soft $T_{1}$.

To prove the supra p-soft regularity of $\left(Y, \mu_{Y}, E\right)$, let $y \in Y$ and $L_{E}$ be a supra soft closed subset of $\left(Y, \mu_{Y}, E\right)$ such that $y \notin L_{E}$. Then there exists a supra soft closed subset $H_{E}$ of $(X, \mu, E)$ such that $L_{E}=\widetilde{Y} \widetilde{\bigcap} H_{E}$ and $y \notin H_{E}$. Therefore, there exist disjoint supra soft open sets $G_{E}$ and $F_{E}$ such that $H_{E} \widetilde{\subseteq} G_{E}$ and $y \in F_{E}$. Now, we find that $L_{E} \widetilde{\subseteq} W_{1_{E}}=\widetilde{Y} \widetilde{\bigcap} G_{E}, y \in W_{2_{E}}=\widetilde{Y} \widetilde{\bigcap} F_{E}$ and $W_{1_{E}} \widetilde{\bigcap} W_{2_{E}}=\widetilde{\Phi}$. Thus, $\left(Y, \mu_{Y}, E\right)$ is supra p-soft regular. Hence, $\left(Y, \mu_{Y}, E\right)$ is supra p-soft $T_{3}$.

Theorem 4.38. Every supra soft closed subspace $\left(Y, \mu_{Y}, E\right)$ of a supra p-soft $T_{4}$-space $(X, \mu, E)$ is a supra p-soft $T_{4}$-space.

Proof. The proof is similar to that of Theorem (3.35).

Proposition 4.39. Let $f_{\phi}:(X, \mu, A) \rightarrow(Y, \theta, B)$ be a soft $S^{\star}$-continuous mapping such that $f$ is an injective mapping. If $(Y, \theta, B)$ is supra $p$-soft $T_{i}$, then $(X, \mu, A)$ is supra $p$-soft $T_{i}$ for $i=0,1,2$.

Proof. We only prove the proposition in the case of $i=1$. The other cases follow similar lines.

Let $x \neq y \in X$. Since $f$ is injective, then $f(x) \neq f(y) \in Y$. By hypothesis, there are two supra soft open subsets $G_{B}$ and $W_{B}$ of $(Y, \theta, B)$ such that $f(x) \in G_{B}, f(y) \notin G_{B}$ and $f(y) \in W_{B}, f(x) \notin W_{B}$. It follows from Proposition (2.16), that $x \in f_{\phi}^{-1}\left(G_{B}\right), y \notin f_{\phi}^{-1}\left(G_{B}\right)$ and $y \in f_{\phi}^{-1}\left(W_{B}\right), x \notin f_{\phi}^{-1}\left(W_{B}\right)$. Since $f_{\phi}$ is soft $S^{\star}$-continuous, then $f_{\phi}^{-1}\left(G_{B}\right)$ and $f_{\phi}^{-1}\left(W_{B}\right)$ are two supra soft open subsets of $(X, \mu, A)$. Hence, $(X, \mu, A)$ is supra p-soft $T_{1}$

For the sake of brevity, we omit the proofs of the following four results.

Proposition 4.40. Let $f_{\phi}:(X, \mu, A) \rightarrow(Y, \theta, B)$ be a bijective soft $S^{\star}$-continuous mapping. If $(Y, \theta, B)$ is supra $p$-soft $T_{i}$, then $(X, \mu, A)$ is supra $p$-soft $T_{i}$ for $i=0,1,2,3,4$.

Proposition 4.41. Let $f_{\phi}:(X, \mu, A) \rightarrow(Y, \theta, B)$ be a bijective soft $S^{\star}$-open mapping. If $(X, \mu, A)$ is supra $p$-soft $T_{i}$, then $(Y, \theta, B)$ is supra $p$-soft $T_{i}$ for $i=0,1,2,3,4$.

Proposition 4.42. Let $f_{\phi}:(X, \mu, A) \rightarrow(Y, \theta, B)$ be a soft $S^{\star}$-homeomorphism mapping. Then $(X, \mu, A)$ is supra $p$-soft $T_{i}$ if and only if $(Y, \theta, B)$ is supra $p$-soft $T_{i}$ for $i=0,1,2,3,4$.

Corollary 4.43. The property of being supra $p$-soft $T_{i}$ is a supra soft topological property, for $i=0,1,2,3,4$.

In the end of this work, we summarize the relationships between the two introduced supra soft separation axioms in the following diagram.

\section{Conclusion and future work}

Soft separation axioms are among the most widespread, important and interesting concepts in soft topology. They can be utilized to construct more restricted classes of soft topological spaces. This, as well as the reasons mentioned in the penultimate paragraph of the introduction section, prompt us to study separation axioms of supra soft topologies in this paper. So we define the concepts of supra soft $T_{i}$-spaces $(i=0,1,2,3,4)$. The fact that we cannot adapt all claims concerning supra topologies to supra soft topologies by using supra soft $T_{i}$-spaces (see, Example (3.12), Example (3.22), Remark (3.30)) leads us to define supra p-soft $T_{i}$-spaces ( $i=$ $0,1,2,3,4)$ which preserve more properties of supra topologies on supra soft topologies (see, Theorem (4.10), Theorem (4.22), Proposition (4.31)). With the help of examples, we explore the relationships between supra 


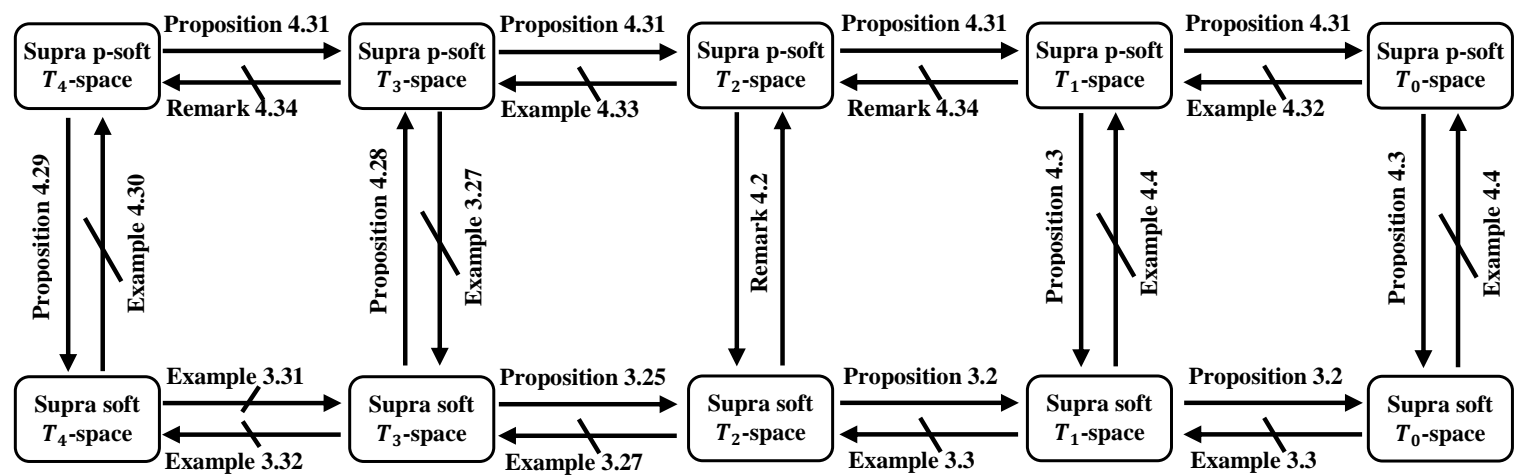

Figure 1: The relationships among some types of supra soft separation spaces.

soft $T_{i}$ and between supra p-soft $T_{i}$; and we study the relationships between supra soft $T_{i}$ and supra p-soft $T_{i}$. Also, we explain the relationships between them and their parametric supra topologies. We further discuss some essential properties of the initiated supra soft axioms. In particular, we characterize the concepts of supra p-soft $T_{i}$-spaces $(i=1,2)$ and supra $\mathrm{p}$-soft regular spaces. We define new notions such as enriched supra soft topologies, supra soft basis and soft $S^{\star}$-continuous mappings; and conclude some results which relate them to some supra soft separation axioms initiated herein.

Eventually, we plan to do the following in the upcoming papers:

(i) Define a concept of supra soft topological ordered spaces in a similar way to the concept of soft topological ordered spaces [38].

(ii) Study a concept of soft lattices [39] with respect to the partial order relations given in [38].

(iii) Investigate the possibility for applications of these two types of supra soft separation axioms in digital and approximation spaces and decision making problems.

(iv) Define a notion soft somewhere dense sets [40] via supra soft topological spaces and generalize supra soft separation axioms initiated herein with respect to this.

Acknowledgements: The authors would like to thank the editors and the referees for their valuable comments which helped us improve the manuscript.

\section{References}

[1] Shabir M., Naz M., On soft topological spaces, Comput. Math. Appl., 2011, 61, 1786-1799

[2] El-Sheikh S. A., Abd El-Latif A. M., Decompositions of some types of supra soft sets and soft continuity, International Journal of Mathematics Trends and Technology, 2014, 9, 37-56

[3] Molodtsov D., Soft set theory - first results, Comput. Math. Appl., 1999, 37, 19-31

[4] Cağman N., Enginoğ S., Soft matrix theory and its decision making, Comput. Math. Appl., 2010, 59, 3308-3314

[5] Yuksel S., Dizman T., Yildizdan G., Sert U., Application of soft sets to diagnose the prostate cancer risk, J. Inequal. Appl., 2013, 2013:229

[6] Karaaslan F., Soft classes and soft rough classes with applications in decision making, Math. Probl. Eng., 2016, Article ID 1584528

[7] Aygünoğlu A., Aygün H., Some notes on soft topological spaces, Neural Comput. \& Applic., 2012, 21, 113-119

[8] Zorlutuna I., Akdag M., Min W. K., Atmaca S., Remarks on soft topological spaces, Ann. Fuzzy Math. Inform., 2012, 2, 171-185

[9] Nazmul S., Samanta S. K., Neighbourhood properties of soft topological spaces, Ann. Fuzzy Math. Inform., 2013, 6(1), 1-15

[10] Das S., Samanta S. K., Soft metric, Ann. Fuzzy Math. Inform., 2013, 6(1), 77-94

[11] Tantawy O., El-Sheikh S. A., Hamde S., Separation axioms on soft topological spaces, Ann. Fuzzy Math. Inform., 2016, 11, 511-525

[12] Singh A., Noorie N. S., Remarks on soft axioms, Ann. Fuzzy Math. Inform., 2017, 14, 503-513 
[13] Bayramov S., Aras C. G., A new approach to separability and compactness in soft topological spaces, TWMS J. Pure Appl. Math., 2018, 9, 82-93

[14] El-Shafei M. E., Abo-Elhamayel M., Al-shami T. M., Partial soft separation axioms and soft compac spaces, Filomat, 2018, 32(13), 4755-4771

[15] Al-shami T. M., Corrigendum to "On soft topological space via semi-open and semi-closed soft sets, Kyungpook Mathematical Journal, 54(2014), 221-236", Kyungpook Math. J., 2018, 58(3), 583-588

[16] Al-shami T. M., Corrigendum to "Separation axioms on soft topological spaces, Ann. Fuzzy Math. Inform., 11(4) (2016) 511525", Ann. Fuzzy Math. Inform., 2018, 15(3), 309-312

[17] El-Shafei M. E., Abo-Elhamayel M., Al-shami T. M., Two notes on "On soft Hausdorff spaces", Ann. Fuzzy Math. Inform., 2018, 16(3), 333-336

[18] Al-shami T. M., Comments on "Soft mappings spaces", The Scientific World Journal, 2019, Article ID 6903809

[19] Mashhour A. S., Allam A. A., Mahmoud F. S., Khedr F. H., On supra topological spaces, Indian J. Pure Appl. Math., 1983, 14(4), 502-510

[20] Al-shami T. M., Some results related to supra topological spaces, J. Adv. Stud. Topol., 2016, 7, 283-294

[21] El-Shafei M. E., Abo-Elhamayel M., Al-shami T. M., On supra $R$-open sets and some applications on topological spaces, Journal of Progressive Research in Mathematics, 2016, 8(2), 1237-1248

[22] Kozae A. M., Shokry M., Zidan M., Supra topologies for digital plane, AASCIT Communications, 2016, 3(1), 1-10

[23] Al-shami T. M., On supra semi open sets and some applications on topological spaces, J. Adv. Stud. Topol., 2017, 8(2), 144-153

[24] Al-shami T. M., Utilizing supra $\alpha$-open sets to generate new types of supra compact and supra Lindelöf spaces, Facta Univ. Ser. Math. Inform., 2017, 32(1), 151-162

[25] Al-shami T. M., Supra semi-compactness via supra topological spaces, Journal of Taibah University for Science, 2018, 12(3), 338-343

[26] El-Shafei M. E., Abo-Elhamayel M., Al-shami T. M., Further notions related to new operators and compactness via supra soft topological spaces, International Journal of Advances in Mathematics, 2019, 1, 44-60

[27] Abd El-latif A. M., Karatas S., Supra b-open soft sets and supra b-soft continuity on soft topological spaces, Journal of Mathematics and Computer Applications Research, 2015, 5(1), 1-18

[28] Kandil A., Tantawy O. A. E., El-Sheikh S. A., Abd El-latif A. M., Notes on $\gamma$-soft operator and some counterexamples on (supra) soft continuity, Ann. Fuzzy Math. Inform., 2015, 10(2), 203-213

[29] Abd El-Latif A. M., Hosny R. A., Supra semi open soft sets and associated soft separation axioms, Appl. Math. Inf. Sci., 2016, 10(6), 2207-2215

[30] Abd El-Latif A. M., Hosny R. A., Supra open soft sets and associated soft separation axioms, International Journal of Advances in Mathematics, 2017, 2(6), 68-81

[31] Khattak A. M., Younas M., Khan G. A., Ur-Rehman M., Nadeem S., Safeer M., P-separation axioms in supra soft topological spaces, Matrix Science Mathematic (MSMK), 2018, 2(2), 07-10

[32] Hosny R. A., Al-Kadi D., Supra soft topology generated from soft topology via soft stack, South Asian Journal of Mathematics, 2017, 7(1), 25-33

[33] Ali M. I., Feng F., Liu X., Min W. K., Shabir M., On some new operations in soft set theory, Comput. Math. Appl., 2009, 57, 1547-1553

[34] Maji P. K., Biswas R., Roy R., Soft set theory, Comput. Math. Appl., 2003, 45, 555-562

[35] Feng F., Li Y. M., Davvaz B., Ali M. I., Soft sets combined with fuzzy sets and rough sets: a tentative approach, Soft Comput, 2010, 14, 899-911

[36] Qin K., Hong Z., On soft equality, J. Comput. Appl. Math., 2010, 234, 1347-1355

[37] Abbas M., Ali M. I., Romaguera S., Generalized operations in soft set theory via relaxed conditions on parameters, Filomat, 2017, 31(19) 5955-5964.

[38] Al-shami T. M., El-Shafei M. E., Abo-Elhamayel M., On soft topological ordered spaces, Journal of King Saud UniversityScience, https://doi.org/10.1016/j.jksus.2018.06.005

[39] Karaaslan F., Çağman N., Enginoğlu S., Soft lattices, Journal of New Results in Science, 2012, 1, 5-17

[40] Al-shami T. M., Soft somewhere dense sets on soft topological spaces, Commun. Korean Math. Soc., 2018, 33(4), 1341-1356 